\title{
GROWTH, PARTIAL ENERGY BALANCE, MANTLE AND DIGESTIVE GLAND LIPID COMPOSITION OF Octopus vulgaris (Cuvier, 1797) FED WITH TWO ARTIFICIAL DIETS.
}

Garcia, S. ${ }^{1}$, Domingues, P. ${ }^{1}$, Navarro, J.C. ${ }^{2}$, Hachero, I. ${ }^{1}$, Garrido, D. ${ }^{1}$, Rosas, C. ${ }^{3}$

${ }^{1}$ Centro IFAPA - Agua del pino. Carretera Punta Umbria, Cartaya, s/n. 21450 CARTAYA. España. Email: sandra.garcia.garrido.ext@juntadeandalucia.es ${ }^{2}$ Instituto de Acuicultura de Torre la Sal (IATS). C. Ribera de Cabañes, s/n. Cabañes, Castellón, España.

${ }^{3}$ Unidad Multidisciplinaria de Docencia e Investigación, Facultad de Ciencias UNAM, Puerto de abrigo s/n Sisal, Mpio. Hunucma, Yucatán, México. 


\begin{abstract}
Effects of two binders (gelatine and alginate), were tested on growth, survival, partial energy balance and lipid composition of mantle and digestive gland of Octopus vulgaris. Octopus average weight was of $713.0 \pm 127.9 \mathrm{~g}$ at the start of the experiment. The three diets tested (10 octopuses per diet) were: 1) CON, (Loligo gahi) as a control diet, 2) GEL, composed of squid paste (L. gahi) (30\%), fish hydrolyse CPSP $^{\circledR}(10 \%)$, and high quality fish meal (50\%), agglutinated with $10 \%$ of gelatine and 3) ALG, composed of squid paste (L. gahi) (30\%), fish hydrolyse CPSP ${ }^{\circledR}(10 \%)$, and high quality fish meal $(50 \%)$, all agglutinated with $10 \%$ of alginate. Growth rates were $1.4 \pm 0.2$, $02 \pm 0.2$ and $-0.2 \pm 0.2 \%$ bw d $^{-1}$, for octopuses fed CON, GEL and ALG diets, respectively, and were higher when fed CON, compared to the two artificial diets. The GEL diet promoted higher growth and none of the artificial diets tested promoted significant growth. The digestive gland of octopuses had higher concentrations of fatty acids than the mantle. Fatty acid composition of the mantle was similar between CON and the two artificial diets. Digestive gland of animals fed CON had higher concentrations of fatty acids, than those fed the artificial diets.
\end{abstract}

Keywords: Binders, lipids, nitrogen excretion, octopus, oxygen consumption.

\title{
Introduction
}

Octopus vulgaris presents high growth rates (Aguado \& Garcia-Garcia, 2003; Iglesias et al., 2006; 2007), high market price (Garcia-Garcia et al., 2004) and great demand throughout many regions of the world, which makes 
it a potential species for aquaculture diversification. The fattening of this species is presently done in Galicia, North Spain (Iglesias et al., 1997), with low profitability, due to the absence of an artificial diet, among other aspects (Garcia-Garcia et al., 2004). In fact, the two major bottlenecks for the commercial aquaculture of this species are the high mortality in the paralarvae stage (Iglesias et al., 2006) and the inexistence of adequate artificial feeds (Domingues et al., 2005; 2006; 2007, Rosas et al., 2007).

Research on artificial diets for cephalopods initiated in the early 90's (Castro, 1991; Lee et al., 1991; Domingues, 1999). Both moist or dry pellets (Castro, 1991; Lee et al., 1991; Castro et al., 1993; Castro \& Lee, 1994) or surimi, a fish myofibrillar protein concentrate (Castro et al., 1993; Castro \& Lee, 1994; Domingues, 1999; Domingues et al., 2005), were initially used, with poor results (Castro et al., 1993; Castro \& Lee, 1994; Domingues et al., 2005; 2006). Recently, either O. vulgaris (Cerezo-Valverde et al., 2008; Quintana et al., 2008) or the Yucatan octopus, Octopus maya (Domingues et al., 2007; Rosas et al., 2007), have been used as research animals to understand the metabolic requirements in order to develop artificial diets.

The use of binders as stabilizers is common practice in aquaculture. Corn and wheat starch, arabic gum, polymers and cellulose, among others, are used as binders (Yamamoto \& Akiyama, 1995). Alginate concentration in diets can alter faeces hardness and reduce pollution (Cho \& Bureau, 2001; Brinker et al., 2005), while its concentration in diets also affects nutrient digestibility (Morales et al., 1993; Arzel et al., 1995). A negative effect of this binder has been reported for sea bass (Dicentrarchus labrax), when inclusions higher than $15 \%$ were used (Gabaudan, 1987).

Cerezo-Valverde et al., (2008) used gelatine and alginate as agglutinants of bogue (Boops boops) and shrimp, to prepare diets for $O$. vulgaris, which promoted negative or moderate growth. However, an artificial wet diet based on crab muscle tissue agglutinated with gelatine was fed to $O$. maya, delivering adequate growth and survival, compared to crab muscle tissue that is commonly used as a control diet (Rosas et al., 2007; Quintana \& Rosas., 2007); diets agglutinated with alginate promoted moderate growth for juveniles of the same species (Aguila et al., 2007). 
Energetics can be defined as the quantification of the exchange and transformations of energy and matter between living organisms and their environment (Lucas, 1993). When applied in nutritional studies, energetics helps to understand how nutrients modulate the physiological mechanisms related with the transformation of food energy into biomass. The basic equation is $\mathrm{I}=\mathrm{H}+\mathrm{U}+\mathrm{R}+\mathrm{P}$ where $\mathrm{I}$ is the ingested energy, $\mathrm{H}$ the energy lost in faeces, $U$ the energy lost in nitrogen metabolism, $R$ the energy invested in respiratory metabolism and $\mathrm{P}$ is the energy invested in production of biomass or gametes. In a practical sense, this equation can provide data regarding how much energy in feeds is necessary for maximum growth rate and how the different proportions of nutrients are used as a source of metabolic energy for growth, or lost as waste products. For several cephalopods, including Pareledone charcoti (Daly \& Peck, 2000), Octopus vulgaris (Petza et al., 2006), Enteroctopus megalocyathus (Pérez et al., 2006; Farias et al., 2009), and Octopus maya (Rosas et al., 2007; Farias et al., 2009) from total ingested energy (100\%), $U$ ranged from 2 to $14 \%$ and $R$ between 23 and $68 \%$. Bioenergetic models are commonly used to estimate growth or consumption in aquatic animals and are very useful to study how types of food modulate the destination of ingested energy. In fact, energetic models allow us to estimate food digestibility, important data for balanced food designs (Lucas, 1993). In aquatic animals, the use of energy from food changes with body weight, mainly because nutritional requirements change during different phases of the life cycle and are also modulated by temperature (Katsanevakis et al., 2005; André et al., 2009; Farias et al., 2009). From an aquaculture point of view, energetic models can be used to calculate the required supply of energy ( $E$ ) as a function of body mass (B). To make an adequate calculation of that value in cephalopods it is necessary to take into account that part of the ingested energy is lost through feces, just before food enters into the hepatopancreas to be digested (Boucher-Rodoni et al., 1987; Lucas, 1993). The differences between energy intake rate (I) and energy lost in faeces $(H)$ is defined as energy absorbed and include respiratory metabolism $(R)$ and biomass production $(P)$. In that sense, $E(B)$ can be calculated as $A b(B)-R(B)-P(B)$, where $E(B)$ must remain positive in order for an individual to survive. The use of this model to test diets for cephalopods could 
be very useful because through $E(B)$ it is possible to integrate the relationship between the digestive and energetic properties of the food and the energetic demands for metabolism and biomass production (André et al., 2009).

The digestive gland (DG) lipid content is considerably higher when compared to the muscle or flesh (Semmens, 1998). This organ plays an important role in lipid digestion and metabolism in cephalopods (Semmens et al., 1995), and there is evidence that it is not used for long term lipid storage (Semmens, 1998; Fluckiger et al., 2008). This organ is also considered to be a good indicator of nutritional status, and is a good candidate to study the effects of different diets in lipid composition of cephalopods, while the mantle is not affected in such magnitude when animals are fed diets that do not fulfill their nutritional requirements. Furthermore, recent studies indicate that fatty acids (FA) play a critical role on nutrition of Octopus vulgaris both during paralarval stages and during growth of juveniles with emphasis in DHA/EPA proportion (docosahexanoic acid (22:6 n-3); EPA, eicosapentanoic acid (20:5 n-3)) as a key factor to explain differences in survival and growth (Navarro \& Villanueva, 2003; Miliou et al., 2005; Okumura et al., 2005) .

The objective of this research was to determine the effects of two binders (gelatine and alginate) on growth, partial energy balance and lipid composition of the mantle and the digestive gland of $O$. vulgaris fed each diet. Frozen squid were used as a control diet, since it has delivered good growth for this species, from previous research (Quintana et al., 2008).

\section{Material and methods}

Artisan bottom trawl nets were used to capture juvenile octopuses $(<1 \mathrm{~kg})$ in coastal waters of Huelva (South Spain). These were immediately brought to the research facility (Centro IFAPA Agua del pino, Cartaya, Spain). Thirty animals were randomly distributed in 30 cylindrical tanks of $80 \mathrm{~L}$ each. Octopuses were fed with squid at $10 \%$ (wet weight of food/wet weight of the animal) (\% bw d $\left.{ }^{-1}\right)$ once a day at 09:00 $\mathrm{h}$. The three diets tested were: 1) CON, squid (Loligo gahi) as a control diet, 2) GEL, composed of squid paste (Loligo gahi) (30\%), fish hydrolyse CPSP $^{\circledR}(10 \%)$, and high quality fish flour 
(50\%), agglutinated with $10 \%$ of gelatine and 3) ALG, composed of squid paste (L. gahi) (30\%), fish hydrolyse CPSP ${ }^{\circledR}(10 \%)$, and high quality fish flour (50\%), all agglutinated with $10 \%$ of alginate.

The high quality fish flower was purchased from PIENSOS MAQUEDA S.L. (Seville, Spain), fish hydrolise $\left(\mathrm{CPSP}^{\circledR}\right)$ was supplied by Sopropeche, (France), while gelatine (Aditio 80-100 Blooms) was purchased from Panreac ${ }^{\circledR}$ (Spain), and alginate (Pokel Merl ${ }^{\circledR}$ and Pokel Cal ${ }^{\circledR}$ ) was purchased from Prosur (Murcia, Spain). There were no differences $(p>0.05)$ in average weights of octopuses fed CON, and the GEL and ALG diets $(713.0 \pm 92.9 \mathrm{~g}$, $708.3 \pm 152.3 \mathrm{~g}$ and $717.8 \pm 144.3 \mathrm{~g}$, respectively) at the start of the experiment, The uneaten remains and faeces from each tank were removed, separated and dried every morning, before feeding. Octopuses were weighted individually every ten days; for every weighing interval, data was used to calculate: 1) Instantaneous growth rate (IGR) $\left(\%\right.$ bw d $\left.{ }^{-1}\right)=((\ln W 2-\ln W 1) / t) x$ 100 , where $W_{2}$ and $W_{1}$ are the final and initial weight of the octopuses, respectively, In the natural logarithm, $t$ the number of days of the experimental period and $\% \mathrm{bwd}^{-1}$ percentage of the body weigh per day, 2) Feeding rate (FR) $\left(\%\right.$ bw d $\left.{ }^{-1}\right)=((F I /$ Average $W(t)) \times 100$, where $\mathrm{Fl}$ is the food ingested and Average $W(t)$ is the average weight of the octopus during that period, and 3 ) Food conversion $(F C)=\left(W_{2}-W_{1}\right) / F I$, where $W_{2}-W_{1}$ is the weight gained by the octopus during that period of time.

Water temperature was $15 \pm 1^{\circ} \mathrm{C}$, with the natural photoperiod between February and March of 2008. Water flow, of $25 \mathrm{~L} \mathrm{~h}^{-1}$, was adjusted in all tanks to maintain oxygen concentration close to saturation levels. The experiment lasted for 30 days. Afterwards, three octopuses fed each diet were placed in respiratory chambers, in order to determine oxygen consumption and nitrogen excretion. At the end of these trials, samples of mantle and DG of 3 octopuses fed each diet were collected in order to calculate lipid composition.

\section{Partial energy balance}

The energy balance equation that represents the energy flow through $O$. vulgaris is $\mathrm{I}=\mathrm{P}+\mathrm{R}$ tot + Utot $+\mathrm{F}$ where $\mathrm{I}$ is the total ingested energy, $\mathrm{P}$ is the energy equivalents of somatic and gonadal growth respectively, Rtot is the energy invested in respiration, Utot is the energy lost as nitrogenous and other 
waste components excreted and $\mathrm{F}$ is the energy unabsorbed voided with the faeces (Lucas, 1993). Total ingested energy was calculated as I = IR $\times$ EFC, where IR is the ingestion rate $\mathrm{g} \mathrm{day}^{-1} \mathrm{Kg}^{-1}$ of animal and EFC is the energy food content (Kjoules $\mathrm{g}^{-1}$ ). The absorbed energy $(\mathrm{Ab})$ was obtained by calculation of the absorbed efficiency $(\mathrm{Ab}, \%)$ defined as: $A E=\left[\left(\mathrm{I}^{\prime}-\mathrm{F}^{\prime}\right) /(1-\right.$ $\left.\left.\mathrm{F}^{\prime}\right) \mathrm{I}^{\prime}\right] \times 100$ (Condrey et al., 1972), where $\mathrm{I}^{\prime}$ is the ratio of the ash free dry weight (afdw) to the dry weight (dw) of the food and $\mathrm{F}^{\prime}$ is the ratio of the afdw to $d w$ of the faeces. The $d w$ and afdw of food and faeces were obtained by placing food and faeces samples at $60^{\circ} \mathrm{C}$ until constant weight and by placing samples in a muffle furnace at $500^{\circ} \mathrm{C}$ for $4 \mathrm{~h}$, respectively. The energy absorbed was calculated as: $\mathrm{Ab}=\mathrm{I}^{*} \mathrm{AE}$.

Energy produced $(\mathrm{P})$ was calculated using the actual growth rate of the octopus obtained during experimental time. The value of $18.8 \pm 0.72 \mathrm{Kj} \mathrm{g}^{-1} \mathrm{dw}$ was used to transform the growth data into production units $\left(\mathrm{P} ; \mathrm{Kj} \mathrm{g}^{-1} \mathrm{dw} \mathrm{d}^{-1}\right)$. This value was obtained from analyzing energy content applied to 10 whole animals by means of a calorimeter (Parr $\left.{ }^{\circledR}\right)$, previously calibrated with benzoic acid.

The oxygen consumption rate and ammonia excretion $\left(\mathrm{mg} \mathrm{h}^{-1}\right)$ were measured in 9 fasting octopuses, at the end of the experiment. Oxygen consumption and ammonia excretion were determined individually by a continuous flow metabolic chamber connected to a flow through system. Measurements were done during 9 hours between 8:30 and 17:30 h. A mean oxygen consumption value was calculated as $\mathrm{VO}_{2}=\mathrm{O}_{2 \mathrm{e}}-\mathrm{O}_{2 \mathrm{ex}} \times \mathrm{Fr}$, where $\mathrm{VO}_{2}$ is oxygen consumption ( $\mathrm{mg} \mathrm{O}_{2} \mathrm{~h}^{-1}$ animal $\left.{ }^{-1}\right), \mathrm{O}_{2 \mathrm{e}}$ indicates oxygen concentration at entrance to the chamber $\left(\mathrm{mg} \mathrm{l}^{-1}\right), \mathrm{O}_{2 e x}$ is oxygen concentration at exit $\left(\mathrm{mg} \mathrm{l}^{-1}\right)$, and $\mathrm{Fr}$ is the flow rate $\left(\mathrm{L} \mathrm{hr}{ }^{-1}\right)$. Oxygen concentration was measured using a digital oxymeter (YSI 50B digital, USA) with a polarographic sensor $\left( \pm 0.01 \mathrm{mg} \mathrm{l}^{-1}\right)$, previously calibrated with oxygensaturated seawater at $15^{\circ} \mathrm{C}$. Ammonia excretion was calculated as $\mathrm{N}-\mathrm{NH}_{3}=$ $\mathrm{NH}_{3 e x}-\mathrm{NH}_{3 e} \times \mathrm{Fr}$, were $\mathrm{N}-\mathrm{NH}_{3}$ indicates ammonia excretion (mg N-NH $\mathrm{H}^{-1}$ animal $\left.{ }^{-1}\right), \mathrm{NH}_{3 e x}$ concentration at the exit of the chamber $\left(\mathrm{mg} \mathrm{l}^{-1}\right), \mathrm{NH}_{3 \mathrm{e}}$ concentration at the entrance of the chamber $\left(\mathrm{mg} \mathrm{l}^{-1}\right) \mathrm{Fr}$ is the flow rate $\left(\mathrm{L} \mathrm{hr}^{-}\right.$ ${ }^{1}$ ). A 14.3 and $20.5 \mathrm{Kj} \mathrm{mg}^{-1}$ conversion factors of oxygen consumption and 
ammonia excretion were used to transform unfed and fed $\mathrm{VO}_{2}$ and $\mathrm{N}-\mathrm{NH}_{3}$ values into energetic units $\left(\mathrm{Kj} \mathrm{h}^{-1}\right.$ animal $\left.{ }^{-1}\right) \mathrm{R}$ and $\mathrm{U}$, respectively (Lucas 1993). Taking into consideration the octopus weight $R$ ) and $U$ were expressed as $\mathrm{Kj} \mathrm{Kg}^{-1} \mathrm{~d}^{-1}$ wet weight (ww) Recorded values of oxygen consumption and ammonia excretion were transformed to $\mu \mathrm{g}-\mathrm{At}_{\mathrm{Kg}} \mathrm{g}^{-1} \mathrm{~h}^{-1}$ and the atomic O:N ratio was estimated.

Assimilated, respiratory and production gross efficiencies were calculated as $R / / \times 100, U / I \times 100$ and $P / I \times 100$, respectively. Respiratory $(R)$ and production net efficiencies (PE) were calculated as $R / A b \times 100$ and $P / A b \times$ 100 , respectively. Required supply of energy ( $E$ ) as a function of body mass ( $B$ $=1 \mathrm{~kg}$ ) was calculated as: $E(B)=A b-R-P$ were all values were expressed as $\mathrm{Kj} \mathrm{kg}^{-1}$ day $^{-1}$.

\section{Lipid composition}

Moisture from diets and octopus mantle and DG, as well as total lipids (TL) and fatty acids of total lipid from mantle and digestive gland of octopus were analysed. Moisture content was determined using the method of Horwitz (1980). Total lipid was extracted with chloroform:methanol (2:1 v/v) containing $0.01 \%$ of butylated hydroxytoluene (BHT) as antioxidant (Christie, 1982). The organic solvent was evaporated under a stream of nitrogen and the lipid content determined gravimetrically. Total lipid (TL) extracts were subjected to acid-catalyzed transmethylation for $16 \mathrm{~h}$ at $50{ }^{\circ} \mathrm{C}$, using $1 \mathrm{ml}$ of toluene and 2 $\mathrm{ml}$ of $1 \%$ sulphuric acid $(\mathrm{v} / \mathrm{v})$ in methanol. The resultant fatty acid methyl esters (FAME) were purified by thin layer chromatography (TLC), and visualized by spraying with $1 \%(\mathrm{w} / \mathrm{v})$ iodine in $\mathrm{CHCl}_{3}$ (Christie, 1982). FAME were separated and quantified by using a Shimadzu GC-2010 gas chromatograph equipped with a flame ionization detector $\left(250^{\circ} \mathrm{C}\right)$ and a fused silica capillary column Tecnokroma Superwax- $280^{\mathrm{TM}}$ (10 m x $0.10 \mathrm{~mm}$ I.D.). Hydrogen was used as carrier gas and samples were applied by on-column injection at an initial temperature of $50^{\circ} \mathrm{C}$. During each analysis, the oven was programmed to rise from 60 to $150{ }^{\circ} \mathrm{C}$ at a rate of $39{ }^{\circ} \mathrm{C} \mathrm{min}^{-1}$, and then to a final temperature of $230^{\circ} \mathrm{C}$ at $2.5^{\circ} \mathrm{C} \mathrm{min}^{-1}$. Individual FAMEs were identified by reference to authentic standards and to a well-characterized fish oil (PUFA-3, 
Biosigma, Spain). BHT, potassium chloride, potassium bicarbonate, iodine were supplied by Sigma Chemical Co (St. Louis, MO). TLC (20x20 cm x 0.25 $\mathrm{mm})$ and HPTLC $(10 \times 10 \mathrm{~cm} \times 0.15 \mathrm{~mm})$ plates, pre-coated with silica gel (without fluorescent indicator) were purchased from Macheren-Nagel (Düren, Germany). All organic solvents for GC used were of reagent grade and were purchased from Panreac (Barcelona, Spain).

\section{Statistics}

Differences in growth and lipid composition of the mantle and digestive gland among the three diets were analyzed with one-way ANOVA. When differences were found, a Tukey multiple comparison test was performed. Homogeneity of variances was verified with the Cochran test. Means obtained during the treatment were compared by using Duncan's multiple range test.

Since in the case of fatty acid composition, it is frequently difficult to interpret the results from the tables, an additional analysis of principal components was performed to determine differences between diets, mantle and DG composition of octopuses fed each diet. Principal components analysis is a statistical method that is normally used to simplify or reduce the number of variables loosing the minimum amount of information possible, without the need to confirm normality and distribution. This makes it easier to understand and explain the results obtained. The new factors or principal components are a lineal combination of the original variables, and are independent between them (Carrasco and Hernán, 1993). A key factor from this type of analysis is to determine the variables that explain the highest variance percentage, and can explain an acceptable proportion of total variance. Therefore, fatty acid data were further chemometrically analysed with Principal Component Analysis (PCA). The score plots obtained after the generation of the two first principal components were used to ascertain groups based on anatomical (mantle, DG) and dietary (ALG, GEL, CON) adscription. The most representative fatty acids and groups, i.e. 14:0, 16:0, 16:4, 18:1n-9, 20:1n-9, 20:2n-6, 20:4n-3, 20:4n-6, 20:5n-3, 22:1n-11, 22:5n-3, 22:6n-3, Saturates, monoenes, PUFA, total $n-3$ and total $n-6$, were selected and introduced in the PCA model. PCA was run iteratively selecting variables 
based on the analysis of the anti image matrix and higher $(>0.4)$ communalities.

All statistical essays were done with the program Spss 17, with a $95 \%$ confidence interval (Zar, 1999).

\section{Results}

Animals fed CON grew significantly higher $(p<0.05)$ compared to the two artificial diets, which were not different between them (Fig. 1; $p>0.05$ ). Final weight of octopuses fed CON, GEL and CAL was 1075.8 $\pm 127.8 \mathrm{~g}$, $712.3 \pm 113.4 \mathrm{~g}$, and $667.8 \pm 134.7 \mathrm{~g}$, respectively. CON also promoted higher $(p<0.05)$ growth rates, while no differences $(p>0.05)$ were found between octopus fed the two artificial diets. Overall growth rates for the experiment were of $1.4 \pm 0.2 \% b w d^{-1}, 0.2 \pm 0.2 \% b w d^{-1}$, and $-0.2 \pm 0.2 \% b w d^{-1}$, for octopuses fed the CON, GEL and ALG diets, respectively. Growth rates were different between all diets $(p<0.05)$, being higher $(p=0.000)$ for the control, while octopuses fed the GEL diet had higher $(p=0.002)$ growth rates than the ones fed the ALG diet. Average feeding rates for octopuses fed CON, GEL and CAL were of $6.9 \pm 0.3 \%$ bw d ${ }^{-1}, 7.1 \pm 0.3 \% b w d^{-1}$, and $7.3 \pm 0.3 \% b w d^{-1}$, respectively, and were not significantly different $(p>0.05)$. Food conversions for animals fed the ALG diet were negative, while values of $21.5 \pm 1.5 \%$ and $3.2 \pm 1.1 \%$ were found for octopuses fed CON and the GEL diet, respectively.

Mortality was $10 \%$ for octopuses fed the GEL diet, while no casualties occurred for animals fed CON or the ALG diet.

\section{Partial energy balance}

The type of diet did not affect the ingestion rate; values between 83 to $89.6 \mathrm{~g} \mathrm{~kg}^{-1}$ day $^{-1}$ were recorded in octopuses fed experimental diets (Table 1; $P>0.05)$. Calorimetric data showed that experimental diets offered different amount of energy; elaborated diets had higher energy content than CON (Table 1; $P<0.05$ ). As a consequence, the type of diet affected the ingested energy with higher values on animals fed ALG bound diet than GEL and control diet, respectively (Table $1 ; \mathrm{P}<0.05$ ). Absorption efficiency $(\%)$ was also affected by type of diet, with higher values in animals fed diet GEL and 
control diet (79.5\% and $82.3 \%$, respectively) than octopuses fed ALG (41\%) (Table 1; $P<0.05)$.

Fasting and feeding oxygen consumption and ammonia excretion measurements were obtained from animals fed three experimental diets (Fig. 2). The oxygen consumption of fasting octopuses fed ALG were lower than registered of animals fed GEL and control diets (Table 2; $P<0.05$ ). After feeding, oxygen consumption of octopuses fed the three diets reached the peak $3 \mathrm{~h}$ after; newly, a higher post prandial oxygen consumption was observed in animals fed GEL and control diets than in animals fed ALG (Fig. 2; $P<0.05)$.

There were no differences between ammonia excretion values registered in animals fed the three experimental diets. A mean value of 307.8 mg N-NH $\mathrm{Kg}^{-1} \mathrm{~h}^{-1}$ was calculated (Table 2; $\mathrm{P}>0.05$ ). After feeding, an increment on ammonia excretion was observed (Fig. 2). Animals fed ALG reached the ammonia excretion peak $2 \mathrm{~h}$ after feeding. In contrast, octopuses fed GEL and CON showed a peak 4 and $6 \mathrm{~h}$ after feeding, respectively (Fig. 2). Post prandial ammonia excretion registered in animals fed the control diet resulted $46 \%$ lower than in animals fed elaborated diets (Table 2; $P<0.05$ ). Fasting and feeding O:N ratio values were between 4 to 15 indicating protein metabolism in animals fed experimental diets (Mayzaud, P. \& Conover, R.J., 1988). Higher values $(p<0.05)$ were recorded in animals fed CON as compared to those fed the elaborated diets (Table 2).

Animals fed the ALG diet were energetically affected by the diet. A negative value of $P$ was recorded in those animals $\left(P=-59.8 \mathrm{Kj} \mathrm{Kg}^{-1}\right.$ day $\left.^{-1}\right)$. In contrast, octopuses fed GEL and CON showed positive $P$ values. However animals fed GEL showed a $P$ value 18 times lower than when fed CON (Table 3; $\mathrm{P}<0.05)$. Once the energetic balance was integrated, it was noticeable that octopuses fed ALG channelled $58 \%$ of ingested energy to $R, 11 \%$ to $U$ and lost $4 \%$ as P. Animals fed GEL channelled $82 \%$ to $R, 11 \%$ to $U$ and $0.9 \%$ to $P$ and octopuses fed CON channelled $77 \%$ to R, $17 \%$ to $U$ and $24 \%$ to $P$ (Fig $3 A)$. The required supply of energy as a function of body mass $E(B)$ was -32 , 84.5 and $154 \mathrm{Kj} \mathrm{Kg}^{-1}$ day $^{-1}$ for octopuses fed ALG, GEL and CON, respectively (Fig. 3B). 


\section{Lipid composition}

Moisture of the three diets (Table 4) and of octopus DG fed these diets (Table 6) was significantly different $(p<0.05)$. Moisture of CON was higher $(p<0.05)$ compared to the artificial diets, while moisture of the GEL diet was also higher $(p<0.05)$ than that of the ALG diet (Table 4). Animals fed the two artificial diets had similar DG moisture $(p=0.773)$, while this was lower in the $D G$ of animals fed CON $(p<0.05)$ (Table 6$)$. Moisture of octopus mantle fed the three diets was similar ( $p>0.05)$ (Table 4).

Total lipid content in $\%$ of dry weight $\left(\% \mathrm{dw}^{-1}\right)$ for the mantle of octopuses fed the tree diets was similar $(p>0.05)$ at the end of the experiment. Results are presented both in percentage of total fatty acids (Table 4$)$ and content $(\mu \mathrm{g} /$ mg DW) (Table 5).

Saturates and monoenes in the mantle of animals fed CON and the GEL diet were similar $(p>0.05)$, and were higher $(p<0.05)$ compared to the ALG diet, in content (Table 5), although in \% of total FA there were no differences in saturates between all diets. For monoenes, only for the ones fed ALG its importance was lower (Table 4). The highest saturated and monoenes were 16:0 and 20:1 n-9, respectively (Tables 4 and 5), and they were lower for animals fed the ALG diet.

The most important n-3 HUFA's were DHA and EPA, and they were similar $(p>0.05)$ for octopuses fed the three diets (Tables 4 and 5 ). The $n-3$ series represent more than $1 / 3$ in percentage of total FA (Table 4).

The most abundant n-6 was arachidonic acid (20:4 n-6, ARA) for all diets, being higher $(p<0.05)$ in those fed the ALG diet, in \% of total FA (Table 4$)$, while there were no differences in content (Table 5 ). The ratio between DHA/EPA was higher $(p<0.05)$ for octopuses fed the ALG diet, while the EPA/ARA and DHA/ARA ratios were higher $(p<0.05)$ for octopuses fed CON (Tables 4).

As for the mantle fatty acid composition, results for DG are presented both in percentage of total fatty acids (Table 6$)$ and in content $(\mu \mathrm{g} / \mathrm{mg} \mathrm{DW}$ ) (Table 7). Total lipid content in $\%$ of dry weight $\left(\% \mathrm{dw}^{-1}\right)$ for the DG of 
octopuses fed CON was higher $(p<0.05)$ than for $G E L$ and $A L G$, while for the ones fed these two artificial it was similar ( $p>0.05$ ) (Table 6).

Concentrations of almost all FA in content were higher in the DG of animals fed CON, compared to the two artificial diets (Table 7). Octopuses fed CON had higher concentration $(p<0.05)$ of monoenes and saturates (Table 7$)$. Contrary, in \% of total fatty acids, monoenes were higher in those fed GEL, while saturates where higher in animals fed ALG (Table 6). The highest saturate was 16:0 and monoenes were 18:1 n-9 (most important in the artificial diets) and 20:1 n-9 (most important in CON) (Tables 6 and 7). The concentration of $16: 0$ was higher $(p<0.05)$ in animals fed CON (Table 7). Contrary, they were similar $(p>0.05)$ in $\%$ of total $F A$, for the ones fed CON and ALG, both higher than for GEL (Table 6).

Higher concentrations $(p<0.05)$ of $n-3$ HUFA were found for the octopuses fed CON, (Tables 6 and 7). This can be explained by the differences in DHA and EPA content. The most important n-3 HUFA were DHA and EPA (Tables 6 and 7). The $n-3$ series represent almost half of total FA in percentage for animals fed CON, while they account for about $1 / 3$ in DG of animals fed the artificial diets (Table 6).

The $n-6$ series was more relatively abundant for animals fed the artificial diets $(p<0.05)$ (Table 6$)$. The most important $n-6$ was ARA for all diets, being higher in animals fed CON (Table 7). Contrary, in relative abundance, it was higher for the ALG diet (Table 6).

The DHA/EPA ratio was similar for octopuses fed the three diets. Contrary, the EPA/ARA and DHA/ARA ratios were higher $(p<0.05)$ for octopuses fed CON, and also higher $(p<0.05)$ for octopuses fed GEL, compared to those fed ALG (Tables 6).

\section{Principal components analysis}

Data selected were well suited for PCA since a value of 0.6 was obtained for the Kaiser- Meyer-Olkin test (KMO) and Bartlett's test for sphericity was highly significant $(\mathrm{P}<0.000)$. The first two principal components generated explained $80 \%$ of total variance $(44.5 \%$ the first component or factor score 1 , and $35.5 \%$ the second or factor score 2) (Figure 4). The analysis of the component matrix after Varimax rotation allowed to associate 
first component to $14: 0$, monoenes and $n-9$ fatty acids on the positive side, and to $n-6$ fatty acids on the negative side. PUFA, especially $n-3$ were strongly associated to the positive side of the second component.

The score plot revealed two distinct groups on the first component mainly identifiable with the DG and Mantle composition, although the DG fatty acid pattern of the ALG group was classified with the mantle results of all the dietary treatments. The second component separated clearly digestive gland fatty acids pattern of CON (associated to higher PUFA3) from that of the GEL group (Figures 4 and 5).

\section{Discussion}

Cephalopods have been fed with artificial diets, with negative or low growth. Domingues et al. $(2005,2008)$ and Ferreira et al. (2009) have fed semi-humid artificial diets to cuttlefish (Sepia officinalis). These diets promoted negative growth. Contrary, moderate growth was obtained using artificial diets for the same species by Domingues (1999), Castro et al. (1993), Castro \& Lee (1994) and Domingues et al. (2005). Also, recently two species of octopuses (O. vulgaris in Spain and O. maya in México) have been fed artificial diets. $O$. vulgaris were fed prepared diets based on shrimp or squid paste agglutinated with gelatine (Quintana et al., 2008), with the diet based on squid paste promoting acceptable growth $\left(1.5 \% \mathrm{bw} \mathrm{d} \mathrm{d}^{-1}\right)$. This artificial diet was a nonprofitable one, from a practical point of view, since it was exclusively based on squid paste, but it demonstrated that gelatine is a good binder for octopus diets.

Recently, Rosas et al. (2008) fed O. maya with an artificial diet based on crab paste agglutinated with either gelatine or alginate. High mortality was observed for octopuses fed the alginate diet, with acceptable growth rates obtained for the diet agglutinated with gelatine $\left(1.91 \pm 0.14 \% \mathrm{bw} \mathrm{d}^{-1}\right)$, which were higher than the control used (crab meat, $1.72 \pm 0.18 \%$ bw d ${ }^{-1}$ ). In the present experiment, higher growth rates (although low, compared to the control) were obtained with the artificial diet agglutinated with gelatine, while animals fed the diet agglutinated with alginate lost weight.

In the present study, genuine prepared ingredients (fish powder, CPSP), were used to feed octopuses, the squid paste (30\%) being the only 
natural component. As in other studies, experimental diets produced lower growth rates in comparison to control groups. Domingues et al. (2007) fed $O$. maya with an artificial diet based on squid paste, CPSP and a pellet used to feed prawns. Octopuses accepted well the artificial diets, but did not grow $\left(0.0 \pm 0.3 \%\right.$ bw d $\left.{ }^{-1}\right)$. Similarly, Rosas et al., (2007) fed the same species with an artificial diet also based in squid paste, CPSP and a pellet used to feed prawns, with good acceptance, but negative growth $\left(-0.08 \% \mathrm{bw} \mathrm{d}^{-1}\right)$.

Aguila et al. (2007), also working with O. maya, used different percentages of CPSP in diets agglutinated with alginate, obtaining growth rates below $1 \%$ bw $\mathrm{d}^{-1}$; this diet delivered better results to the ones obtained here, also agglutinated with alginate and similar concentrations of CPSP. We have several hypotheses to possibly explain the marginal growth or no-growth rates obtained when feeding octopuses with prepared diets. One could be due to changes in protein structure during elaboration, due to denaturation by heating (Domingues et al., 2009), avoiding the enzyme attack during the chymo formation, which could affect the digestibility. There are evidences that demonstrate that meat cooking affected myofibrillar protein susceptibility to proteases, reducing, the meat digestibility (Santé-Lhoutellier et al., 2008; Gatellier \& Santé-Lhoutellier, 2009).

Also another hypothesis could be related with the during food elaboration. During protein processes, amino acids and some lipids could also be lost, reducing the nutritional quality of the diet and affecting the growth rate, not via the digestibility, but via the changes of nutritional characteristics. In fact, results from energetic balance demonstrate that physiologically useful energy for animal maintenance $E(B)$ was affected by type of diet. A negative value of $E(B)$ was observed in animals fed $A L G$, while positive (85 and $154 \mathrm{Kj}$ $\mathrm{Kg}^{-1}$ day $^{-1}$ ) were observed in octopuses fed GEL and CON, respectively. It is evident that the ALG diet did not cope the physiological requirements for octopus growth. In contrast positive values were observed for animals fed GEL and CON. Value of $E(B)$ of animals fed the GEL diet was $44 \%$ lower than the $E(B)$ value observed in animals fed $C O N$, suggesting that nutritional characteristics of the diet affect in different forms the physiologically useful energy of experimental animals. In the case of the GEL diet, it is evident that although that diet was well accepted by animals, they invested a lot of energy 
into the respiratory metabolism (82\%) reducing the energy available to biomass production. This is typical of animals fed with diets that do not cover the nutritional requirements, as demonstrated by Pérez et al. (2006) for Enteroctopus megalocyathus.

Although lipids usually account for less than $2 \%$ in cephalopods (Almansa et al., 2006), their importance is much higher in the DG. This organ contains 4 to 5 times more lipids and lipase activity compared to the mantle (Moltschanlwskyj \& Johnston, 2006). The DG plays an important role in lipid digestion and metabolism, with several functions as enzyme secretion, digestion and absorption (Semmens et al., 1995). Contrary, there is evidence that the DG is not used to store lipids (Moltschanlwskyj \& Johnston, 2006; Fluckiger et al., 2008), which makes it a good candidate to study the effects of different diets in lipid composition of this organ for cephalopods.

Absolute concentrations of almost all FA in content obtained in the present study were higher $(p<0.05)$ in the DG of animals fed CON, compared to the two artificial diets (Table 7). This can be explained by the much larger amounts of lipids, almost 4 times higher, compared to the ones of octopuses fed the prepared diets. For the mantle, there are a few differences when comparing some FA in qualitative (Table 4) and quantitative data (Table 5), mainly in saturates, ARA and $n-6$.

The most abundant fatty acids (both in content and \% of total FA) in the mantle of octopuses fed either the natural diet (CON) or the artificial diets in this study (Tables 4 and 5) were palmitic acid (16:0), EPA (20:5 n-3) and DHA $(22: 6 \mathrm{n}-3)$. This has also been reported for cuttlefish (Sinanoglou and MiniadisMeimaroglou, 1998; Zlatanos et al., 2006; Ferreira et al., 2009) Eledone moschata (Sinanoglou and Meimaroglou, 1998), O. vulgaris (Miliou et al., 2006; Zlatanos et al., 2006), Todarodes sagittatus (Sinanoglou \& MiniadisMeimaroglou, 1998), and Loligo vulgaris (Zlatanos et al., 2006). Similarly, and in agreement with Ferreira et al. (2009), these three FA were the most abundant in the DG.

The mantle of cuttlefish fed artificial diets did not show differences (in absolute concentration) between monoenes, saturates and PUFA, compared to natural diets (Ferreira et al., 2009). This pattern was different in the present experiments for monoenes and saturates using $O$. vulgaris, since animals fed 
the ALG diet (which promoted negative growth) had lower concentrations of these fatty acid groups (Table 5). The DG of cuttlefish fed artificial diets showed lower contents of saturates, monoenes and PUFA, compared to natural diets (Ferreira et al., 2009), and this pattern was confirmed in the present experiments (Table 7). Marine species use monoenes as energy substrates (Sargent et al., 1995), contrary to cephalopods that present an amino acid based metabolism (Domingues, 1999). This could explain the lower concentration of these fatty acids in the composition of the mantle $(<12 \%)$ and DG of cuttlefish (22 to $33 \%$ of total FA) (Ferreira et al., 2009) and in the present experiment the mantle (10 to 13\%) (Table 4) and DG of octopuses fed CON (less than $25 \%$, Table 6 ).

The DHA/EPA ratio varied between 1.4 and 1.6 in the mantle, being higher for animals fed the ALG diet which promoted negative growth, and could indicate a most extensive use of EPA by these animals, that were in worse condition due to their feeding on a deficient diet. This ratio is similar to those reported for the mantle of $O$. vulgaris by Zlatanos et al., (2006) (1.5), Miliou et al., (2006), (between 1.5 and 1.9) and by Sinanoglou \& MiniadisMeimaroglou (1998) (1.5).

The DHA/EPA ratio varied between 1.8 and 2.1 in the DG of $O$. vulgaris in this study (Table 6 ), being similar between the natural and artificial diets, which can be explained by the simultaneous decrease of both FA in DG of animals fed the two deficient diets. We have not found information in the bibliography consulted about dietary effects on the DHA/EPA ratios for $O$. vulgaris. Nevertheless, lower ratios in the DG of $S$. officinalis when feeding crustaceans (between 0.3 and 0.6), or when feeding on fish (between 1.5 and 1.8) were reported by Fluckiger et al., (2008). Ferreira et al. (2009) also indicates lower ratios for DG of $S$. officinalis, $(<0.5)$, with significant differences between those fed crustaceans (between 0.2 and 0.5 ) and artificial diets (between 0.9 and 1.0).

Increase in ARA is related to growth in O. vulgaris mantle (Miliou et al., 2006). Results obtained here showed no differences in ARA absolute concentrations between diets (Table 5), and an opposite pattern in \% of total FA, since octopuses with higher growth rates had less ARA than those with lower growth rates (Table 4). 
In conclusion, none of the two artificial diets promoted satisfactory growth, but gelatine proved to be a more adequate binder. Acceptance was good, and growth was comparable to the one obtained by other authors using higher percentages of natural feeds such as fish, squid or prawn, in the elaboration of the artificial diets.

The lower growth obtained with the artificial diets was greatly reflected in total lipid composition of the DG, and consequently the fatty acid composition of this organ. It is interesting to verify that the FA composition of the mantle of octopuses fed all diets was similar, according to the principal components analysis (Figure 4). This can be explained by the fact that the mantle is a much more metabolically stable organ, and even in periods of underfeeding or feeding on nutritional deficient diets, FA are not removed rapidly from this tissue. This fact was also observed for cuttlefish by Ferreira et al., (2009), that reported no differences in FA mantle composition when fed different diets, even some that promoted negative growth. Also, octopuses that were fed the ALG diet and lost weight had DG composition that was similar to their mantle and mantle of octopuses fed the other diets (Figure 4). This also confirms that those animals fed the ALG diet were indeed in worse condition. Further confirmations are obtained when analyzing the principal components for octopuses fed the three diets (Figure 5). In this case, diet did not affect mantle composition in FA, but it greatly affected DG composition, and in a greater extent for animals fed the ALG diet. The majority of the most important fatty acid groups, such as n-3 PUFA, as well as important fatty acids, such as EPA and DHA decreased in the DG of animals fed the artificial diets, which indicates that these animals were in worse condition, compared to the ones fed CON. However differences in energetic balance were observed between diets, indicating that GEL was adequately digested but probably failed in nutritional characteristics (as fatty acids proportion; amino acids, etc.) that affect the biomass production.

\section{Acknowledgements}

The authors wish to thank the "Plan Nacional de pulpo" - JACUMAR Project "Engorde de pulpo, Octopus vulgaris." 2007/2009, and the project 
CONACYT -Basico 50118 of C.R. from the Mexican government, for the funding for this research. Sandra García whishes to thank the "Instituto Nacional de Investigación y Tecnología Agraria y Alimentaria" (INIA) for the Pre-doctoral grant no 47 (BOE no 308 26/12/2006).

\section{References}

Aguado-Giménez, F. \& García-García, B. (2003) Growth and food intake models in Octopus vulgaris Cuvier (1797): influence of body weight, temperature, sex and diet. Aquacult. Int., 10, 361-377.

Aguila, J., Cuzon, G., Pascual, C., Domingues, P., Gaxiola, G., Sánchez, A., Maldonado, T. \& Rosas, C. (2007) The effects of fish hydrolysate (CPSP) level on Octopus maya (Voss and Solis) diet: digestive enzyme activity, blood metabolites, and energy balance. Aquaculture, 273, 641-655.

Almansa, E., Domingues, P., Sykes, A., Tejera, N., Lorenzo, A. \& Andrade, J. (2006) The effects of feeding with shrimp or fish fry on growth and mantle lipid composition of juvenile and adult cuttlefish (Sepia officinalis). Aquaculture, 256, 403-413.

André, J., Grist, E.P.M., Semmens, J.M., Pecl, G. \& Segawa, S. (2009) Effects of temperature on energetics and the growth pattern of benthic octopuses. J. Exp. Mar. Biol. Ecol., 374, 167-179.

Arzel, J., Métailler, R., Kerleguer, C., Le Delliou, H. \& Guillaumme, J. (1995) The protein requirement of brown trout (Salmo trutta) fry. Aquaculture, 130, 67-78.

Boucher-Rodoni, R., Boucaud-Camou, E. \& Mangold, K., (1987) Feeding and digestion. In: Cephalopod Life Cycles (Boyle, P., ed.). pp. 85-108. Academic Press, London. 
Brinker, A., Koppe, W. \& Rosch, R. (2005) Optimised effluent treatment by stabilised trout faeces. Aquaculture, 249, 125-144.

Carrasco, J.L. \& Hernán, M.A. (1993) Estadística multivariante en las ciencias de la vida. In: Fundamentos, métodos y aplicación. pp. 65-75. (Editorial Ciencia 3, S.L.) Madrid, España.

Castro, B.G. (1991) Can Sepia officinalis L. be reared on artificial food? Mar. Behav. Physiol., 19, 35-38.

Castro, B., DiMarco, F.P., DeRusha, R.H. \& Lee, P.G. (1993) The effects of surimi and pelleted diets on the laboratory survival, growth, and feeding rate of the cuttlefish Sepia officinalis L. J. Exp. Mar. Biol. Ecol., 170, 241-252.

Castro, B.G. \& Lee, P.G. (1994) The effects of semi-purified diets on growth and condition of Sepia officinalis L. (Mollusca: Cephalopoda). Comp. Biochem. Physiol., 109, 1007-1016.

Cerezo-Valverde, J., Hernández, M., Aguado-Giménez, F. \& García García, B. (2008) Growth, feed efficiency and condition of common octopus (Octopus vulgaris) fed on two formulated moist diets. Aquaculture, 275, 266-273.

Cho, C. \& Bureau, D. (2001) A review of diet formulation strategies and feeding systems to reduce excretory and feed wastes in aquaculture. Aquac. Res., 32, 349-360.

Condrey, R.E., Gosselink, J.G. \& Bennet, H.J. (1972) Comparison of the assimilation of different diets by Penaeus setiferus and Penaeus aztecus. Fish. Bull., 70, 1281-1291.

Christie, W.W. (1982) Lipids analysis, $2^{\text {nd }}$ edition. Oxford: Pergamon Press. 
Daly, H.I. \& Peck, L.S. (2000) Energy balance and cold adaptation in the octopus Pareledone charcoti. Mar. Biol. \& Ecol., 245, 197-214.

Domingues, P. (1999) Development of alternative diets for the mass culture of the European cuttlefish Sepia officinalis. PhD thesis, University of the Algarve, Portugal, $95 \mathrm{p}$.

Domingues, P.M., DiMarco, F.P., Andrade, J.P. \& Lee, P.G. (2005) The effects of diets with amino acid supplementation on the survival, growth and body composition of the cuttlefish Sepia officinalis. Aquac. Int., 13, 423-440.

Domingues, P., Bettencourt, V. \& Guerra, A. (2006) Growth of Sepia officinalis in captivity and in nature. Vie Millieu, 56, 109-120.

Domingues, P., López, N., Muñoz, J., Maldonado, T., Gaxiola, G. \& Rosas, C. (2007) Effects of an artificial diet on growth and survival of the Yucatán octopus, Octopus maya. Aquac. Nut., 13, 273-280.

Domingues, P., Ferreira, A., Márquez, L., Andrade, J., López, N. \& Rosas, C. (2008) Growth, absorption and assimilation efficiency by mature cuttlefish (Sepia officinalis) fed with alternative and artificial diets. Aquacult. Int., 16, 215-229.

Domingues, P., Márquez, L., López, N. \& Rosas, C. (2009) Effects of food termal treatment on growth, absorption and assimilation efficiency of juvenile cuttlefish, Sepia officinalis. Aquacult. Int., DOI 10.1007/s10499-008-9200-z.

Farias, A., Uriarte, I., Hernández, J., Pino, S., Pascual, C., Caamal, C., Domingues, P. \& Rosas, C. (2009) How size relates to oxygen consumption, ammonia excretion, and ingestion rates in cold (Enteroctopus megalocyathus) and tropical (Octopus maya) octopus species. Mar. Biol., 156, 1547-1558.

Ferreira, A., Marquez, L., Almansa, E., Andrade, J., Lorenzo, A. \& Domingues, P. (2009) The use of alternative diets to culture juvenile cuttlefish, Sepia 
officinalis: Effects on growth and lipid composition. Aquac. Nut., DOI 10.1111/j.1365-2095.2009.00661.x.

Fluckiger, M., Jackson, G.D., Nichols, P., Virtue, P., Daw, A. \& Wotherspoon, S. (2008) An experimental study of the effect of diet on the fatty acid profiles of the European Cuttlefish (Sepia officinalis). Mar. Biol., 154, 363-372.

Gabaudan, J. (1987) Studies of nutrients ADC in sea bass (Dicentrarchus labrax). II. Effects of Na Alginate on Protein and Lipid. Nutrition Series. Ifremer publication, pp. 1-8.

García-García, J., Rodríguez-González, L.M. \& García-García, B. (2004) Cost analysis of octopus ongrowing installation in Galicia. Spanish Journal of Agricult. Res., 2, 531-537.

Gatellier, P. \& Santé-Lhoutellier, V. (2009) Digestion study of proteins from cooked meat using an enzymatic microreactor. Meat Science, 81, 405-409.

Horwitz, W. (1980) Methods of analysis, $13^{\text {th }}$ edition. Washington D.C. Association of Official Analytical Chemists.

Iglesias, J., Sánchez, F.J. \& Otero, J.J. (1997) Primeras experiencias sobre el cultivo integral del pulpo (Octopus vulgaris Cuvier) en el I.E.O. In: Actas del VI C. Nacional de Acuicultura. (Costa, J., Abellán, E., García, B., Ortega, A., Zamora, S. eds.), pp. 221-226. ISBN: 84-491-0323-1. Cartagena, España.

Iglesias, J., Fuentes, L., Sánchez, J., Otero, J.J., Moxica, C. \& Lago, M.J. (2006) First feeding of Octopus vulgaris Cuvier, 1797 paralarvae using Artemia: effect of prey size, prey density and feeding frequency. Aquaculture, 261, 817-822.

Iglesias, J., Sánchez, F.J., Bersano, J.G.F., Carrasco, J.F., Dhont, J., Fuentes, L., Linares, F., Muñoz, J.L., Okumura, S., Roo, J., van der Meeren, T., Vidal, 
E.A.G. \& Villanueva, R. (2007) Rearing of Octopus vulgaris paralarvae: Present status, bottlenecks and trends. Aquaculture, 266, 1-15.

Katsanevakis, S., Protopapas, N., Miliou, H. \& Verriopoulos, G. (2005) Effect of temperature on specific dynamic action in the common octopus Octopus vulgaris (Cephalopoda). Mar. Biol., 146, 733-738.

Lee, P.G., Forsythe, J.W., DiMarco, F.P., DeRusha, R. \& Hanlon, R.T. (1991) Initial palatability and growth trials on pelleted diets for cephalopods. Bull. Mar. Sci., 49, 362-372.

Lucas, A. (1993) Bioénergétique Des Animaux Aquatiques. Masson, Paris.

Mayzaud, P., \& Conover, R.J. (1988). O:N atomic ratio as a tool to describe zooplankton metabolism. Mar. Ecol. Prog. Ser. 45, 289-302.

Miliou, H., Fintikaki, M., Kountouris, T. \& Verriopoulos, G. (2005) Combined effects of temperature and body weight on growth and protein utilization of the common octopus Octopus vulgaris. Aquaculture, 249, 245-256.

Miliou, H., Fintikaki, M., Tzitzinakis, M., Kountouris, T. \& Verriopoulos, G. (2006) Fatty acid composition of the octopus, Octopus vulgaris, in relation to rearing temperature and body weight. Aquaculture, 256, 311-322.

Moltschanlwskyj, N.A. \& Johnston, D. (2006) Evidence that lipid can be digested by the dumpling squid Euprymna tasmanica, but is not stored in the digestive gland. Mar. Biol., 149, 565-572.

Morales, A., Cardenete, G., Sanz, A., Akharbach, H. \& de la Higuera, M. (1993) Influence of different binders on dietary availability of nutrients in rainbow trout. Colloq. INRA (France) 34, Paris. 
Navarro, J.C. \& Villanueva, R. (2003) The fatty acid composition of Octopus vulgaris paralarvae reared with live and inert food: deviation from their natural fatty acid profile. Aquaculture, 219, 613-631.

Okumura, K., Kurihara, A., Iwamoto, A. \& Takeuchi, T. (2005) Improved survival and growth in Octopus vulgaris paralarvae by feeding large type Artemia and Pacific sandeel, Ammodytes personatus. Aquaculture, 244, 147157.

Pérez, M.C., López, D.A., Aguila, K. \& González, M.L. (2006) Feeding and growth in captivity of the octopus Enteroctopus megalocyathus. Aquac. Research, 37, 550-555.

Petza, D., Katsanevakis, S. \& Verriopoulos, G. (2006) Experimental evaluation of the energy balance in Octopus vulgaris, fed ad libitum on a high-lipid diet. Marine Biology, 148, 827-832.

Quintana, D. \& Rosas, C. (2007) Estudio de la influencia de la ración de alimento sobre la actividad enzimática digestiva de juveniles tempranos de Octopus maya y su relación con el crecimiento y supervivencia, empleando una dieta artificial húmeda. X Foro Iberoamericano dos Recursos Mariños e da Acuicultura das Rías Galegas e I Foro Iberoamericano dos Recursos Mariños e da Acuicultura,10 e 11 de outubro do 2007, Illa de A Toxa (O Grove), España.

Quintana, D., Domingues, P. \& Garcia, S. (2008) Effects of two artificial wet diets agglutinated with gelatin on feed and growth performance of common octopus (Octopus vulgaris) sub-adults. Aquaculture, 280, 161-164. 
Rosas, C., Cuzon, G., Pascual, C., Gaxiola, G., López, N., Maldonado, T. \& Domingues, P. (2007) Energy balance of Octopus maya fed crab and artificial diet. Mar. Biol., 152, 371-378.

Rosas, C., Tut, J., Baeza, J., Sánchez, A., Sosa, V., Pascual, C., Arena, L., Domingues, P. \& Cuzon, G. (2008) Effect of type of binder on growth, digestibility, and energetic balance of Octopus maya. Aquaculture, 275, 291297.

Santé-Lhoutellier, V., Astruct, T., Marinova, P., Greve, E. \& Gatellier, P. (2008) Effect of meat cooking on physicochemical state and in vitro digestibility of myofibrillar proteins. J. Agric. Food. Chem., 56, 1488-1494.

Sargent, J.R., Bell, J.G., Henderson, R.J. \& Tocher, D.R. (1995) Origins and functions of $\mathrm{n}-3$ polyunsaturated fatty acids in marine organisms. In: Phospholipods: Characterization, Metabolism and Novel Biochemical applications (Ceve, G. \& Paltauf, F. eds.) pp. 248-259. Champaign, IL: American Oil Chemical Society Press.

Semmens, J.M., Moltschaniwskyj, N.A. \& Alexander, C.G. (1995) Effect of feeding on the digestive gland of the tropical sepioid Idiosepius pygmaeus. $J$. Mar. Biol. Ass. U.K., 75, 885-897.

Semmens, J.M. (1998) An examination of the role of the digestive gland of two loliginid squids, with respect to lipid: Storage or excretion ? Proc. R. Soc. Lond., 265, 1685-1690.

Sinanoglou, V.J. \& Miniadis-Meimaroglou, S. (1998) Fatty acid of neutral and polar lipids of (edible) Mediterranean cephalopods. Food Res. Int., 31(6-7), 467-473.

Yamamoto, T. \& Akiyama, T. (1995) Effect of carboxymethylcellulose, alphastarch, and wheat gluten incorporated in diets as binders on growth, feed 
efficiency, and digestive enzyme activity of fingerling Japanese flounder. Fisheries Sci., 61, 309-313.

Zar, J.H. (1999) Biostatistical analysis (Ryu, T. ed.) 4th ed., 663 p. PrenticeHall Inc., Upper Saddle River, NJ.

Zlatanos, S., Laskaridis, K., Feist, C. \& Sagredos, A. (2006) Proximate composition, fatty acid analysis and protein digestibility-corrected amino acid score of three Mediterranean cephalopods. Mol. Nutr. Food Res., 50, 967-970.

Table 1 - Ingestion rate $\left(\mathrm{g} \mathrm{kg}^{-1}\right.$ day $\left.{ }^{-1}\right)$, absorbed energy and ingested energy of $O$. vulgaris fed squid bound alginate (ALG) and gelatin (GEL). Fresh squid used as control diet $(C O N)$. Values as Mean $\pm S$.E. Different letters indicate statistical differences at $\mathrm{P}<0.05$ level.

\begin{tabular}{|c|c|c|c|c|c|c|c|c|c|c|c|c|c|c|}
\hline \multirow[b]{2}{*}{ ALG } & \multicolumn{2}{|c|}{$\begin{array}{l}\text { Ingestion Rate } \\
\mathrm{g} \mathrm{kg}^{-1} \mathrm{day}^{-1} \\
\end{array}$} & \multicolumn{3}{|c|}{$\begin{array}{c}\text { Energy of Food } \\
\mathrm{kj} \mathrm{g}^{-1} \\
\end{array}$} & & \multicolumn{3}{|c|}{$\begin{array}{l}\text { Ingested energy } \\
\mathrm{Kj} \mathrm{kg}^{-1} \text { day }^{-1} \\
\end{array}$} & & \multicolumn{4}{|c|}{$\begin{array}{c}\text { Absorption Efficiency } \\
\% \\
\end{array}$} \\
\hline & 89.56 & $\pm 0.92^{a}$ & 17.35 & \pm & 0.26 & $\bar{b}$ & 1553.82 & \pm & 16.04 & ${ }^{c}$ & 40.80 & \pm & 3.71 & a \\
\hline GEL & 83.26 & $\pm 1.34^{\mathrm{a}}$ & 17.00 & \pm & 0.31 & b & 1415.42 & \pm & 22.81 & b & 79.50 & \pm & 6.36 & b \\
\hline CON & 87.38 & $+0.51^{a}$ & 14.48 & + & 0.21 & a & 1265.30 & \pm & 6.96 & $a$ & 82.30 & + & 6.50 & 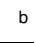 \\
\hline
\end{tabular}


1

2

3

4

5

6

7

8

9

10

11

12

13

14

Table 2 - Oxygen consumption and ammonia excretion of $O$. vulgaris fed squid bound alginate (ALG) and gelatin (GEL). Fresh squid used as control diet $(\mathrm{CON})$. Values are Mean \pm S.E. Different letters indicate statistical differences at $P<0.05$ level.

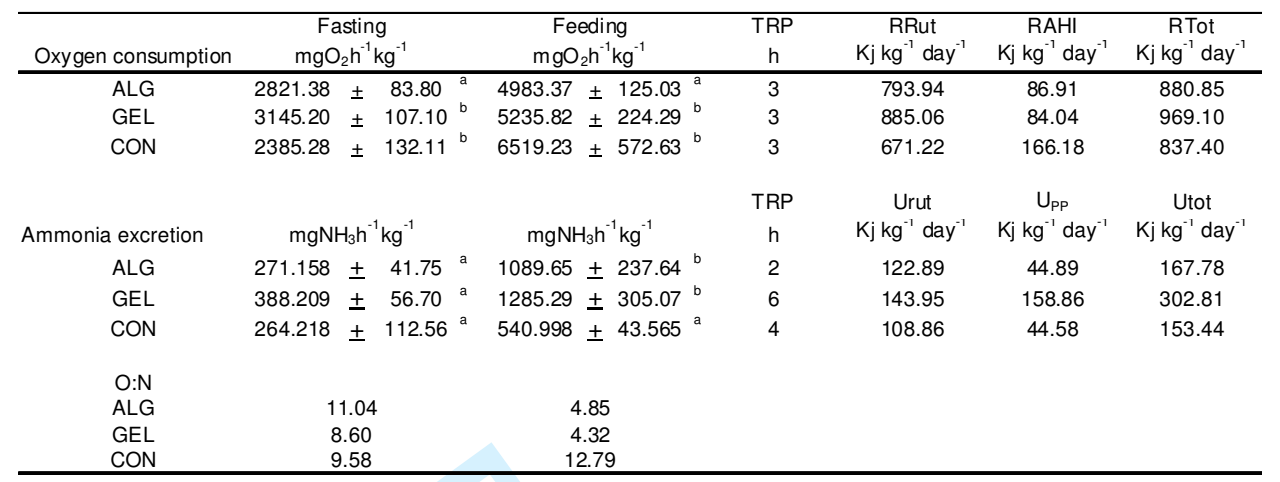

TRP $=$ Time to reach the peak. RRut $=$ Routine Respiratory metabolism, $\mathrm{RAHI}=$ Apparent heat increment Respiratory metabolism. RTot $=$ Total respiratory metabolism (RRut + RAHI), Urut $=$ Routine Nitrogen metabolism. Upp $=$ Post prandial nitrogen metabolism, Utot $=$ Total Nitrogen metabolism (Urut + Upp). 
Table 3 - Energy production $\left(\mathrm{P}, \mathrm{Kj} \mathrm{Kg}^{-1} \mathrm{day}^{-1}\right.$ ) of $O$. vulgaris juveniles fed experimental diets: Alginate (ALG), Gelatine (GEL) y Squid (CON). Values as mean \pm S.E. Different letters indicate statistical differences at $P<0.05$ level.

\begin{tabular}{ccccc}
\hline & ALG & GEL & CON \\
\hline Initial weight, g & $717.77 \pm 45.63^{\mathrm{a}}$ & $692.34 \pm 42.9^{\mathrm{a}} 713.0 \pm 42.9^{\mathrm{a}}$ \\
Final weight, g & $618.16 \pm 65.88^{\mathrm{a}}$ & $712.32 \pm 35.9^{\mathrm{b}}$ & $1075.8 \pm 35.9^{\mathrm{c}}$ \\
Experimental Days & 30 & 30 & 30 & \\
Production Kj Kg $^{-1}$ day $^{-1}$ & $-59.76 \pm 8.51^{\mathrm{a}}$ & $12.0 \pm 5.62^{\mathrm{b}}$ & $217.6 \pm 4.68^{\mathrm{c}}$ \\
\hline
\end{tabular}

Table 4 - Diet moisture (\%ww), Mantle moisture (\%ww), Total Lipids (\% DW) of octopus mantle and Fatty acids of total lipids (\% weight) of octopuses mantle fed squid (CON) and two artificial diets (GEL, ALG).

\begin{tabular}{|c|c|c|c|}
\hline Diet composition & CON & GEL & ALG \\
\hline Diet moisture & $80,5 \pm 1,9$ a & $58,4 \pm 2,1 \quad$ b & $49,9 \pm 1,6 \mathrm{c}$ \\
\hline Mantle moisture & $78,6 \pm 2,5$ & $80,2 \pm 2,0$ & $81,6 \pm 2,5$ \\
\hline Mantle Total Lipids & $5,2 \pm 0,6$ & $4,6 \pm 0,7$ & $4,1 \pm 0,6$ \\
\hline 14:0 & $1,87 \pm 0,38 \quad a$ & $1,45 \pm 0,43 \quad a b$ & $1,06 \pm 0,06 \quad b$ \\
\hline 15:0 & $0,43 \pm 0,01$ & $0,37 \pm 0,03$ & $0,39 \pm 0,10$ \\
\hline UK 1 & $1,64 \pm 0,11 \quad a$ & $1,45 \pm 0,16 \quad a b$ & $1,36 \pm 0,12 \quad b$ \\
\hline $16: 0$ & $23,88 \pm 3,31 \quad$ a & $21,84 \pm 0,55 a b$ & $19,58 \pm 1,91$ \\
\hline $16: 1 n-7$ & $1,18 \pm 0,11$ & $1,39 \pm 0,34$ & $0,94 \pm 0,21$ \\
\hline $16: 1 n-5$ & $0,32 \pm 0,02$ & $0,28 \pm 0,03$ & $0,31 \pm 0,05$ \\
\hline $17: 0$ & $1,12 \pm 0,08 \quad a$ & $1,41 \pm 0,14 \quad a b$ & $1,46 \pm 0,17 \quad b$ \\
\hline $16: 4$ & $3,40 \pm 0,42 \quad \mathbf{a}$ & $5,02 \pm 0,64 \quad$ b & $5,43 \pm 0,61 \quad b$ \\
\hline $18: 0$ & $7,19 \pm 0,88$ & $8,98 \pm 1,57$ & $9,07 \pm 0,58$ \\
\hline $18: 1 n-9$ & $2,77 \pm 0,36 \quad a b$ & $3,07 \pm 0,59 \quad \mathbf{a}$ & $2,16 \pm 0,30 \quad b$ \\
\hline $18: 1 n-7$ & $1,74 \pm 0,16$ & $1,77 \pm 0,22$ & $1,42 \pm 0,18$ \\
\hline $18: 2 n-6$ & $0,46 \pm 0,01$ & $0,47 \pm 0,08$ & $0,49 \pm 0,18$ \\
\hline $20: 1 n-9$ & $3,55 \pm 0,31 \quad a$ & $3,42 \pm 0,27 \quad \mathbf{a}$ & $2,82 \pm 0,16 \quad b$ \\
\hline $20: 2 n-6$ & $0,41 \pm 0,03$ & $0,36 \pm 0,04$ & $0,37 \pm 0,07$ \\
\hline $20: 4 n-6$ & $2,97 \pm 0,90 \quad \mathbf{a}$ & $4,47 \pm 1,31 \quad a b$ & $6,17 \pm 1,06 \quad b$ \\
\hline $20: 4 n-3$ & $0,19 \pm 0,03 \quad a$ & $0,13 \pm 0,04 \quad a b$ & $0,11 \pm 0,03 \quad b$ \\
\hline $20: 5 n-3$ & $15,65 \pm 1,25$ & $13,32 \pm 0,90$ & $13,95 \pm 2,08$ \\
\hline 22:1 n-11 & $0,12 \pm 0,01 \quad a b$ & $0,35 \pm 0,16 \quad \mathbf{a}$ & $0,06 \pm 0,05 \quad b$ \\
\hline 22:1 n-9 & $1,45 \pm 0,26$ & $1,81 \pm 0,23$ & $1,57 \pm 0,23$ \\
\hline $22: 5 n-3$ & $0,86 \pm 0,08 \quad a$ & $0,89 \pm 0,07 \quad a$ & $1,08 \pm 0,12 \quad b$ \\
\hline
\end{tabular}


1

2

3

4

5

6

7

8

9

10

11

12

13

14

15

16

17

18

19

20

21

22

23

24

25

26

27

28

29

30

31

32

33

34

35

36

37

38

39

40

41

42

43

44

45

46

47

48

49

50

51

52

53

54

55

56

57

58

59

60

\begin{tabular}{|c|c|c|c|}
\hline 22:6n-3 & $21,77 \pm 2,38$ & $18,43 \pm 1,55$ & $21,65 \pm 2,15$ \\
\hline UK & $3,66 \pm 0,54$ & $5,01 \pm 0,94$ & $4,83 \pm 1,18$ \\
\hline \multicolumn{4}{|l|}{ Totals } \\
\hline Saturates & $34,60 \pm 3,96$ & $34,21 \pm 1,27$ & $31,74 \pm 2,09$ \\
\hline Monoenes & $12,13 \pm 1,03 \quad a b$ & $13,14 \pm 1,63 \quad \mathbf{a}$ & $10,28 \pm 0,93$ \\
\hline PUFA & $44,57 \pm 4,42$ & $41,17 \pm 2,51$ & $46,36 \pm 3,80$ \\
\hline$n-3$ & $39,54 \pm 3,51$ & $33,85 \pm 2,31$ & $37,75 \pm 4,24$ \\
\hline$n-6$ & $4,40 \pm 1,06 \quad \mathbf{a}$ & $6,37 \pm 1,16 \quad a b$ & $7,98 \pm 1,12 \quad$ b \\
\hline$n-9$ & $7,77 \pm 0,79 \quad \mathbf{a}$ & $8,30 \pm 0,78 \quad$ a & $6,54 \pm 0,30 \quad$ b \\
\hline $\mathrm{n}-3$ HUFA & $38,68 \pm 3,56$ & $33,08 \pm 2,36$ & $37,10 \pm 4,24$ \\
\hline$n-3 / n-6$ & $9,25 \pm 1,68$ a & $5,43 \pm 0,94 \quad b$ & $4,84 \pm 1,20 \quad$ b \\
\hline DHA/EPA & $1,39 \pm 0,10 \quad a b$ & $1,38 \pm 0,07 \quad a$ & $1,54 \pm 0,09 \quad \mathbf{b}$ \\
\hline EPA/ARA & $5,56 \pm 1,40 \quad$ a & $3,15 \pm 0,80 \quad \mathbf{b}$ & $2,34 \pm 0,68 \quad b$ \\
\hline DHA/ARA & $7,73 \pm 1,95$ a & $4,34 \pm 1,11 \quad b$ & $3,62 \pm 0,89 \quad$ b \\
\hline Mon/n-3 H & $0,32 \pm 0,05 \quad a b$ & $0,40 \pm 0,07 \quad \mathbf{a}$ & $0,28 \pm 0,05 \quad b$ \\
\hline Mon/PUFA & $0,28 \pm 0,05 \quad a b$ & $0,32 \pm 0,06 \quad \mathbf{a}$ & $0,22 \pm 0,04 \quad b$ \\
\hline Mon/Sat & $0,35 \pm 0,03$ & $0,38 \pm 0,05$ & $0,32 \pm 0,02$ \\
\hline 18:1n-9/n3 HUFA & $0,07 \pm 0,01 \quad a b$ & $0,09 \pm 0,02 \quad \mathbf{a}$ & $0,06 \pm 0,01 \quad b$ \\
\hline
\end{tabular}

UK, unknown fatty acids; PUFA, polyunsaturated fatty acid; HUFA, highly unsaturated fatty acid; DHA, docosahexanoic acid (22:6 n-3); EPA, eicosapentanoic acid (20:5 n-3); ARA, arachidonic acid (22:4 n6); Mon, monounsaturated fatty acid; Sat, saturated fatty acid. Letters show significant differences $(p<0.05)$. Values as mean \pm S.D.

Table 5 - Fatty acids of total lipids $(\mu \mathrm{g} / \mathrm{mg} \mathrm{DW}$ ) of the mantle of octopuses fed the squid (CON) and two artificial diets (GEL, ALG).

\begin{tabular}{|c|c|c|c|}
\hline Diet composition & CON & GEL & ALG \\
\hline $14: 0$ & $0,39 \pm 0,13 \quad \mathbf{a}$ & $0,26 \pm 0,07 a b$ & $0,15 \pm 0,03 \quad b$ \\
\hline 15:0 & $0,09 \pm 0,01 \quad \mathbf{a}$ & $0,07 \pm 0,01 \quad b$ & $0,05 \pm 0,01 \quad b$ \\
\hline UK 1 & $0,33 \pm 0,03 \quad a$ & $0,26 \pm 0,02 a b$ & $0,20 \pm 0,06 \quad b$ \\
\hline $16: 0$ & $4,87 \pm 0,70 \quad \mathbf{a}$ & $3,96 \pm 0,53 \quad \mathbf{a}$ & $2,77 \pm 0,38 \quad b$ \\
\hline $16: 1 n-7$ & $0,24 \pm 0,06 \quad \mathbf{a}$ & $0,25 \pm 0,05 \quad \mathbf{a}$ & $0,13 \pm 0,01 \quad b$ \\
\hline $16: 1 n-5$ & $0,07 \pm 0,01 \quad \mathbf{a}$ & $0,05 \pm 0,00 \quad \mathbf{b}$ & $0,04 \pm 0,01 \quad b$ \\
\hline $17: 0$ & $0,23 \pm 0,02$ & $0,26 \pm 0,04$ & $0,21 \pm 0,02$ \\
\hline $16: 4$ & $0,69 \pm 0,04$ & $0,91 \pm 0,16$ & $0,78 \pm 0,22$ \\
\hline 18:0 & $1,46 \pm 0,04$ & $1,63 \pm 0,36$ & $1,31 \pm 0,33$ \\
\hline $18: 1 \mathrm{n}-9$ & $0,57 \pm 0,14 \quad \mathbf{a}$ & $0,55 \pm 0,07 \quad \mathbf{a}$ & $0,30 \pm 0,04 \quad b$ \\
\hline $18: 1 n-7$ & $0,36 \pm 0,07 \quad \mathbf{a}$ & $0,32 \pm 0,04 \quad \mathbf{a}$ & $0,20 \pm 0,03 \quad b$ \\
\hline $18: 2 n-6$ & $0,10 \pm 0,02 \quad a$ & $0,08 \pm 0,00 a b$ & $0,07 \pm 0,02 \quad b$ \\
\hline $20: 1 n-9$ & $0,73 \pm 0,16 \quad \mathbf{a}$ & $0,62 \pm 0,07 \quad \mathbf{a}$ & $0,40 \pm 0,07 \quad b$ \\
\hline $20: 2 n-6$ & $0,08 \pm 0,02 \quad \mathbf{a}$ & $0,07 \pm 0,01 a b$ & $0,05 \pm 0,00 \quad b$ \\
\hline $20: 4 n-6$ & $0,61 \pm 0,21$ & $0,82 \pm 0,30$ & $0,89 \pm 0,30$ \\
\hline $20: 4 n-3$ & $0,04 \pm 0,01 \quad a$ & $0,02 \pm 0,01 a b$ & $0,02 \pm 0,01 \quad b$ \\
\hline $20: 5 n-3$ & $3,23 \pm 0,64$ & $2,43 \pm 0,47$ & $2,04 \pm 0,67$ \\
\hline
\end{tabular}


UK, unknown fatty acids; PUFA, polyunsaturated fatty acid; HUFA, highly unsaturated fatty acid. Letters show significant differences $(p<0.05)$. Values as mean \pm S.D.

Table 6 - Digestive gland moisture (\%ww), Total Lipids (\%dw) of octopus digestive gland and Fatty acid of total lipids (\% dw) of octopuses digestive gland fed squid (CON) and two artificial diets (GEL, ALG).

\begin{tabular}{|c|c|c|c|}
\hline Diet composition & CON & GEL & ALG \\
\hline DG moisture & $66,7 \pm 1,2 \quad \mathbf{a}$ & $74,6 \pm 2,3 \quad \mathbf{b}$ & $75,7 \pm 2,1 \quad$ b \\
\hline DG Total Lipids & $36,5 \pm 6,7 \quad \mathbf{a}$ & $12,9 \pm 2,1 \quad b$ & $9,7 \pm 2,2 \mathbf{b}$ \\
\hline $14: 0$ & $3,87 \pm 0,11 \quad a$ & $3,77 \pm 0,74 \quad a$ & $1,64 \pm 0,34 \quad b$ \\
\hline $15: 0$ & $0,58 \pm 0,03 \quad a$ & $0,73 \pm 0,10 \quad \mathbf{b}$ & $0,35 \pm 0,05 \quad \mathbf{c}$ \\
\hline UK 1 & $0,73 \pm 0,12 \quad a$ & $1,00 \pm 0,34 \quad a b$ & $1,27 \pm 0,13 \quad \mathbf{b}$ \\
\hline $16: 0$ & $20,71 \pm 0,56 \quad \mathbf{a}$ & $18,83 \pm 0,84 \quad$ b & $19,72 \pm 0,61 a b$ \\
\hline $16: 1 n-7$ & $2,06 \pm 0,15 \quad a$ & $4,75 \pm 0,53 \quad$ b & $1,92 \pm 0,36 \quad a$ \\
\hline $16: 1 n-5$ & $0,32 \pm 0,02 \quad a$ & $0,38 \pm 0,04 \quad a$ & $0,24 \pm 0,03 \quad b$ \\
\hline $17: 0$ & $0,58 \pm 0,04 \quad a$ & $0,89 \pm 0,11 \quad b$ & $1,02 \pm 0,07 \quad \mathbf{b}$ \\
\hline $16: 4$ & $0,59 \pm 0,05 \quad a$ & $1,55 \pm 0,34 \quad \mathbf{b}$ & $3,49 \pm 0,79$ c \\
\hline $18: 0$ & $3,89 \pm 0,26 \quad \mathbf{a}$ & $6,43 \pm 0,62 \quad b$ & $10,77 \pm 1,24 \quad$ c \\
\hline $18: 1 n-9$ & $3,99 \pm 0,24 \quad a$ & $6,89 \pm 0,79 \quad \mathbf{b}$ & $3,95 \pm 0,89 \quad \mathbf{a}$ \\
\hline $18: 1 n-7$ & $2,36 \pm 0,13 \quad a$ & $2,61 \pm 0,10 \quad a$ & $1,92 \pm 0,23 \quad \mathbf{b}$ \\
\hline $18: 2 n-6$ & $0,46 \pm 0,02 \quad a$ & $0,92 \pm 0,09 \quad \mathbf{b}$ & $0,54 \pm 0,01 \quad a$ \\
\hline $20: 1 n-9$ & $4,94 \pm 0,39$ & $5,18 \pm 2,54$ & $2,70 \pm 0,26$ \\
\hline $20: 2 n-6$ & $0,56 \pm 0,02 \quad a$ & $0,42 \pm 0,10 \quad b$ & $0,33 \pm 0,02 \quad \mathbf{b}$ \\
\hline $20: 4 n-6$ & $1,49 \pm 0,07 \quad \mathbf{a}$ & $2,43 \pm 0,30 \quad$ b & $5,12 \pm 0,52 \quad \mathbf{c}$ \\
\hline $20: 4 n-3$ & $0,31 \pm 0,02 \quad a b$ & $0,43 \pm 0,10 \quad a$ & $0,17 \pm 0,07 \quad \mathbf{b}$ \\
\hline $20: 5 n-3$ & $14,64 \pm 0,25 \quad \mathbf{a}$ & $9,79 \pm 1,74 \quad$ b & $11,15 \pm 1,41$ \\
\hline 22:1 n-11 & $0,31 \pm 0,08$ & $2,61 \pm 2,57$ & $0,64 \pm 0,07$ \\
\hline
\end{tabular}


1

2

3

4

5

6

7

8

9

10

11

12

13

14

15

16

17

18

19

20

21

22

23

24

25

26

27

28

29

30

31

32

33

34

35

36

37

38

39

40

41

42

43

44

45

46

47

48

49

\begin{tabular}{|c|c|c|c|}
\hline $22: 1 \mathrm{n}-9$ & $0,94 \pm 0,07$ & $1,13 \pm 0,36$ & $1,10 \pm 0,11$ \\
\hline $22: 5 n-3$ & $0,62 \pm 0,02 \quad a$ & $1,03 \pm 0,19 \quad \mathbf{b}$ & $1,00 \pm 0,11 \quad b$ \\
\hline $22: 6 n-3$ & $29,10 \pm 1,25 \quad \mathbf{a}$ & $18,09 \pm 4,50 \quad$ b & $23,18 \pm 1,76 a b$ \\
\hline$\%$ UK & $2,69 \pm 0,28 \quad \mathbf{a}$ & $5,47 \pm 1,75 \quad$ b & $3,81 \pm 1,63 \quad a b$ \\
\hline \multicolumn{4}{|l|}{ Totals } \\
\hline Saturates & $29,71 \pm 0,90 \quad \mathbf{a}$ & $30,76 \pm 0,79$ a & $33,70 \pm 0,41 \quad b$ \\
\hline Monoenes & $15,93 \pm 0,67 \quad \mathbf{a}$ & $24,79 \pm 6,00 \quad$ b & $13,29 \pm 0,33 \quad a$ \\
\hline PUFA & $50,34 \pm 1,69 \quad \mathbf{a}$ & $36,42 \pm 7,43 \quad$ b & $44,46 \pm 2,60 a b$ \\
\hline$n-3$ & $46,42 \pm 1,53 \quad$ a & $30,56 \pm 6,71 \quad b$ & $36,45 \pm 3,42 \quad$ b \\
\hline$n-6$ & $2,84 \pm 0,15 \quad a$ & $4,28 \pm 0,56 \quad$ b & $6,49 \pm 0,46 \quad c$ \\
\hline$n-9$ & $9,88 \pm 0,63 \quad a b$ & $13,20 \pm 3,61 \quad$ a & $7,75 \pm 0,53 \quad$ b \\
\hline n-3 HUFA & $44,84 \pm 1,41 \quad$ a & $29,46 \pm 6,53 \quad$ b & $35,62 \pm 3,40 a b$ \\
\hline$n-3 / n-6$ & $16,35 \pm 0,40 \quad \mathbf{a}$ & $7,08 \pm 0,91 \quad$ b & $5,66 \pm 0,90 \quad$ b \\
\hline DHA/EPA & $1,99 \pm 0,06$ & $1,83 \pm 0,16$ & $2,09 \pm 0,12$ \\
\hline EPA/ARA & $9,85 \pm 0,32 \quad \mathbf{a}$ & $4,02 \pm 0,45 \quad$ b & $2,21 \pm 0,47 \quad \mathbf{c}$ \\
\hline DHA/ARA & $19,58 \pm 0,09 \quad \mathbf{a}$ & $7,38 \pm 1,37 \quad$ b & $4,58 \pm 0,77 \quad \mathbf{c}$ \\
\hline Mon/n-3 H & $0,36 \pm 0,03$ & $0,92 \pm 0,51$ & $0,37 \pm 0,03$ \\
\hline Mon/PUFA & $0,32 \pm 0,02$ & $0,74 \pm 0,39$ & $0,30 \pm 0,01$ \\
\hline Mon/Sat & $0,54 \pm 0,01 \quad a$ & $0,81 \pm 0,21 \quad b$ & $0,39 \pm 0,01 \quad a$ \\
\hline 18:1n-9/n3 HUFA & $0,09 \pm 0,01 \quad \mathbf{a}$ & $0,25 \pm 0,10 \quad$ b & $0,11 \pm 0,02 \quad \mathbf{a}$ \\
\hline
\end{tabular}

DG, digestive gland; UK, unknown fatty acids; PUFA, polyunsaturated fatty acid; HUFA, highly unsaturated fatty acid; DHA, docosahexanoic acid (22:6 n-3); EPA, eicosapentanoic acid $(20: 5$ n-3); ARA, arachidonic acid (22:4 n-6); Mon, monounsaturated fatty acid; Sat, saturated fatty acid. Letters show significant differences $(p<0.05)$. Values as mean \pm S.D.

Table 7 - Fatty acid of total lipids ( $\mu \mathrm{g} / \mathrm{mg} \mathrm{DW}$ ) of octopuses digestive gland fed squid (CON) and two artificial diets (GEL, ALG).

\begin{tabular}{|c|c|c|c|c|c|}
\hline Diet composition & CON & GEL & & ALG & \\
\hline $14: 0$ & $9,55 \pm 1,89$ a & $2,57 \pm 0,97$ & b & $0,53 \pm 0,22$ & b \\
\hline $15: 0$ & $1,42 \pm 0,25 \quad \mathbf{a}$ & $0,47 \pm 0,12$ & b & $0,11 \pm 0,02$ & b \\
\hline UK 1 & $1,76 \pm 0,09 \quad \mathbf{a}$ & $0,62 \pm 0,15$ & b & $0,39 \pm 0,08$ & 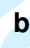 \\
\hline $16: 0$ & $50,93 \pm 8,86 \quad$ a & $12,50 \pm 3,51$ & b & $6,24 \pm 1,75$ & b \\
\hline $16: 1 n-7$ & $5,14 \pm 1,39 \quad \mathbf{a}$ & $3,18 \pm 1,02$ & $\mathbf{a}$ & $0,62 \pm 0,25$ & b \\
\hline $16: 1 \mathrm{n}-5$ & $0,79 \pm 0,16 \quad a$ & $0,25 \pm 0,07$ & $\mathbf{b}$ & $0,07 \pm 0,01$ & . \\
\hline $17: 0$ & $1,42 \pm 0,18 \quad a$ & $0,58 \pm 0,13$ & b & $0,32 \pm 0,09$ & b \\
\hline $16: 4$ & $1,43 \pm 0,17 \quad \mathbf{a}$ & $0,98 \pm 0,11$ & b & $1,06 \pm 0,07$ & b \\
\hline $18: 0$ & $9,52 \pm 1,44 \quad \mathbf{a}$ & $4,18 \pm 0,88$ & b & $3,32 \pm 0,53$ & b \\
\hline $18: 1 \mathrm{n}-9$ & $9,82 \pm 1,77 \quad \mathbf{a}$ & $4,45 \pm 0,83$ & b & $1,29 \pm 0,55$ & c \\
\hline $18: 1 n-7$ & $5,80 \pm 1,01 \quad a$ & $1,72 \pm 0,42$ & b & $0,59 \pm 0,09$ & b \\
\hline $18: 2 n-6$ & $1,16 \pm 0,24 \quad \mathbf{a}$ & $0,62 \pm 0,19$ & b & $0,17 \pm 0,05$ & c \\
\hline $20: 1$ n-9 & $12,08 \pm 1,67 \quad \mathbf{a}$ & $3,10 \pm 0,43$ & b & $0,84 \pm 0,15$ & \\
\hline $20: 2 n-6$ & $1,39 \pm 0,33 \quad \mathbf{a}$ & $0,29 \pm 0,12$ & b & $0,10 \pm 0,02$ & b \\
\hline
\end{tabular}




\begin{tabular}{|c|c|c|c|c|c|}
\hline $20: 4 n-6$ & $3,69 \pm 0,88 \quad \mathbf{a}$ & $1,64 \pm 0,58$ & b & $1,59 \pm 0,27$ & b \\
\hline $20: 4 n-3$ & $0,76 \pm 0,12 \quad a$ & $0,30 \pm 0,12$ & b & $0,06 \pm 0,03$ & c \\
\hline $20: 5 n-3$ & $36,22 \pm 7,81 \quad$ a & $6,69 \pm 2,56$ & b & $3,58 \pm 1,27$ & b \\
\hline 22:1 n-11 & $0,74 \pm 0,17 \quad a b$ & $1,40 \pm 0,83$ & a & $0,20 \pm 0,07$ & b \\
\hline $22: 1 n-9$ & $2,31 \pm 0,42 \quad \mathbf{a}$ & $0,70 \pm 0,06$ & b & $0,34 \pm 0,06$ & b \\
\hline $22: 5 n-3$ & $1,54 \pm 0,27 \quad a$ & $0,70 \pm 0,27$ & b & $0,32 \pm 0,10$ & b \\
\hline $22: 6 n-3$ & $72,24 \pm 17,10$ a & $12,50 \pm 5,43$ & $\mathbf{b}$ & $7,39 \pm 2,32$ & b \\
\hline$\%$ UK & $6,76 \pm 1,26 \quad$ a & $3,52 \pm 1,07$ & b & $1,12 \pm 0,14$ & c \\
\hline \multicolumn{6}{|l|}{ Totals } \\
\hline Saturates & $73,07 \pm 12,63$ a & $20,38 \pm 5,51$ & b & $10,59 \pm 2,61$ & b \\
\hline Monoenes & $39,15 \pm 6,69 \quad \mathbf{a}$ & $15,60 \pm 1,29$ & b & $4,20 \pm 1,15$ & c \\
\hline PUFA & $124,87 \pm 28,68 \mathbf{a}$ & $25,00 \pm 10,03$ & $3 \mathbf{b}$ & $14,13 \pm 4,26$ & b \\
\hline$n-3$ & $115,13 \pm 26,39 \mathbf{a}$ & $21,02 \pm 8,66$ & $\mathbf{b}$ & $11,65 \pm 3,83$ & b \\
\hline$n-6$ & $7,07 \pm 1,71 \quad$ a & $2,91 \pm 1,03$ & b & $2,02 \pm 0,40$ & b \\
\hline$n-9$ & $24,21 \pm 3,83 \quad$ a & $8,26 \pm 0,53$ & b & $2,47 \pm 0,76$ & c \\
\hline n-3 HUFA & $111,16 \pm 25,29 \mathbf{a}$ & $20,27 \pm 8,40$ & b & $11,39 \pm 3,75$ & b \\
\hline
\end{tabular}

UK, unknown fatty acids; PUFA, polyunsaturated fatty acid; HUFA, highly unsaturated fatty acid. Letters show significant differences $(p<0.05)$. Values as mean \pm S.D.

Figure 1. Weights (g) of common octopus fed with squid (CON) and two artificial diets (GEL and ALG) for the different weighing periods. Bars indicate standard deviations.

Figure 2. Oxygen consumption ( $\mathrm{mg} \mathrm{O}_{2} \mathrm{~kg}^{-1} \mathrm{~h}^{-1}$ ) and ammonia excretion ( $\mathrm{mg} \mathrm{N}$ $\mathrm{NH}_{3} \mathrm{~kg}^{-1} \mathrm{~h}^{-1}$ ) of $O$. vulgaris juveniles fed experimental diets. Data as mean \pm S.E. Arrow indicates time when octopuses were fed.

Figure 3A. Energetic balance of $O$. vulgaris juveniles fed three experimental diets (ALG, GEL, CON). Values into the columns are as $\mathrm{Kj} \mathrm{Kg}^{-1} \mathrm{~h}^{-1}$, while percentage indicate proportion of each value as Ingestion rate $(I=100 \%)$.

Figure 3B. Effect of type of diet on dietary supply of energy $E(B)$ as a function of body mass $E(B)$ for octopuses fed CON, GEL and ALG.

Figure 4. Results for the principal components analysis for FA composition of the DG and mantle of octopuses used in the experiment. 
1

3

Figure 5. Results for the principal components analysis for FA composition of the octopuses fed the tree diets tested.
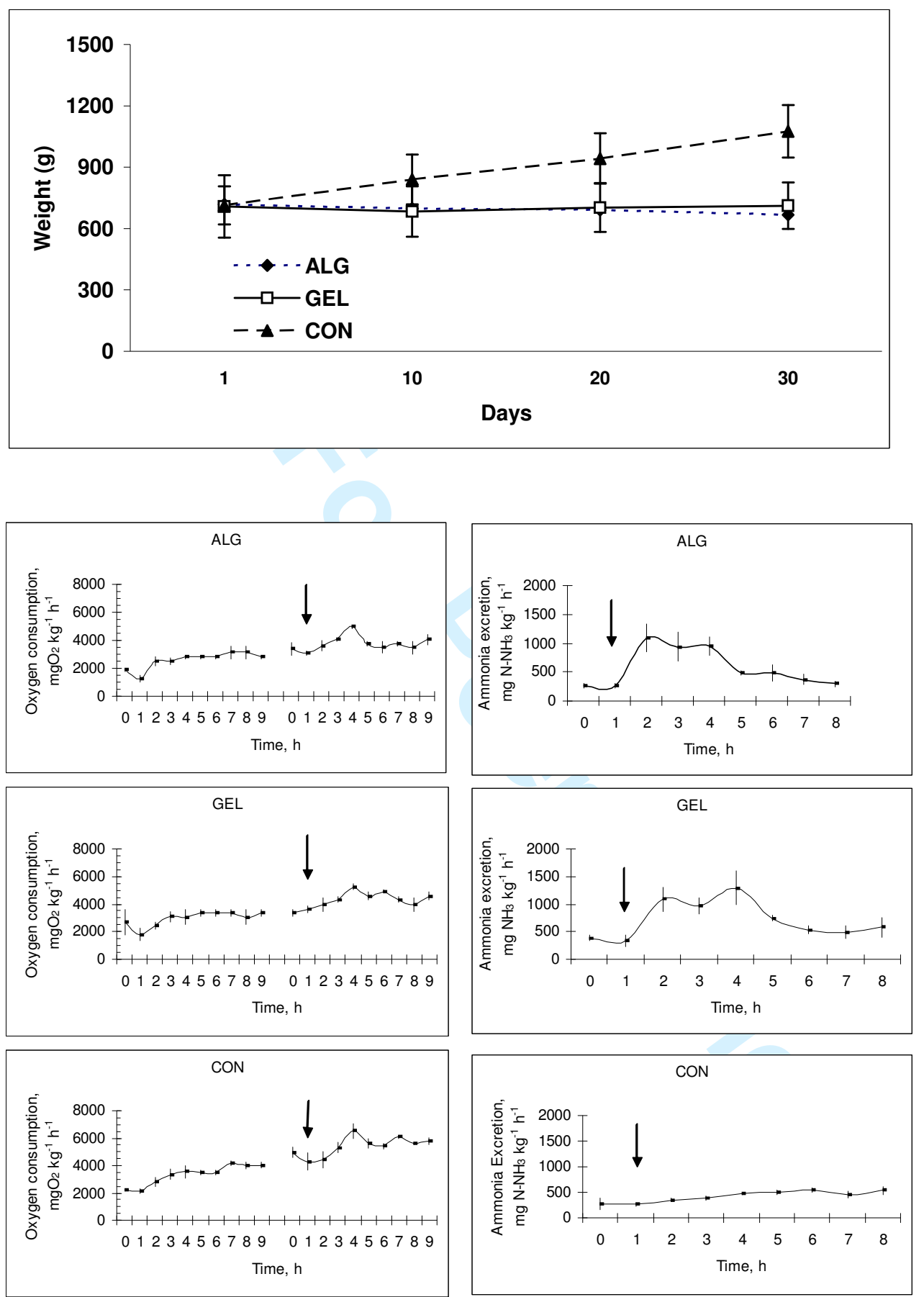

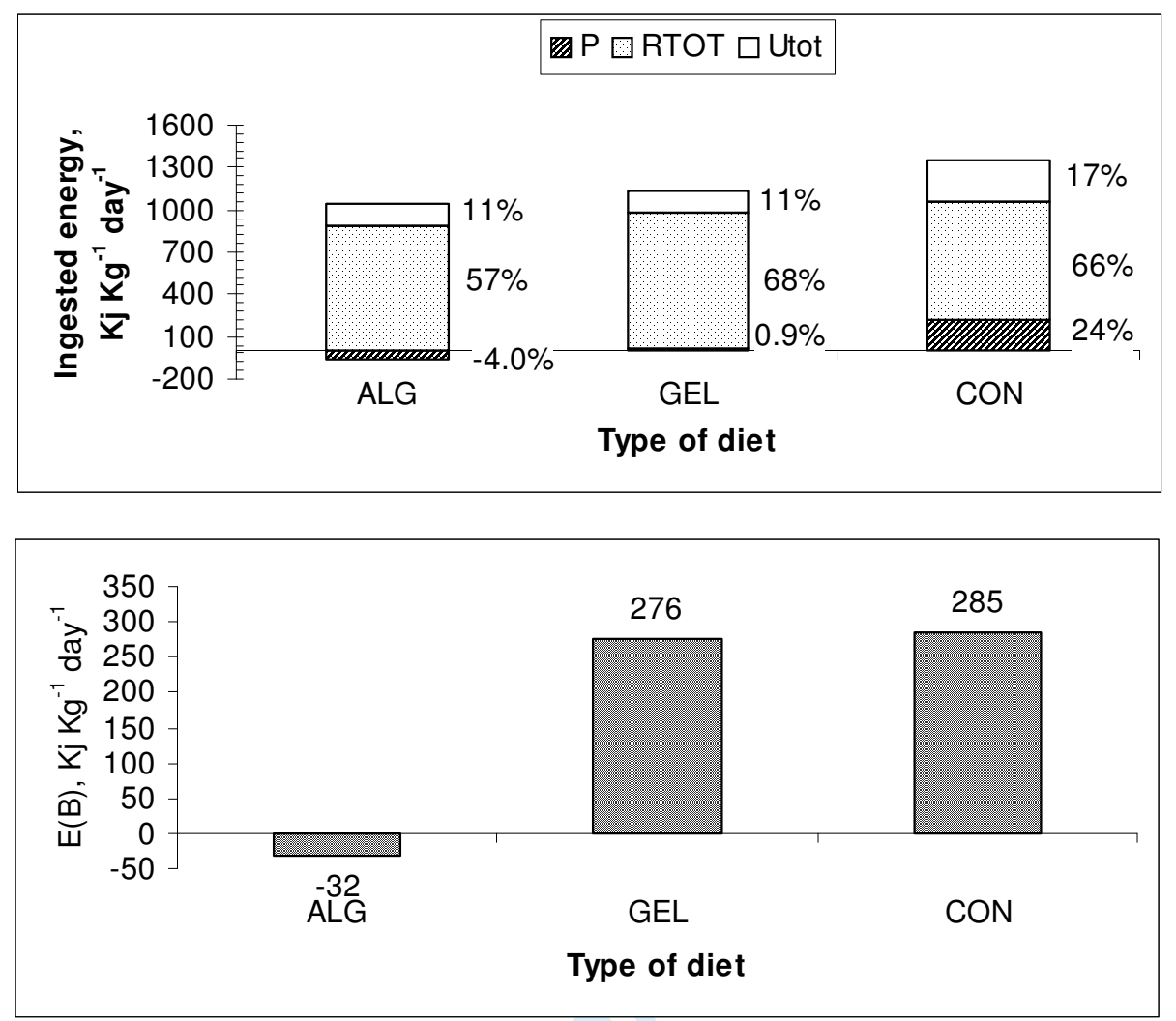


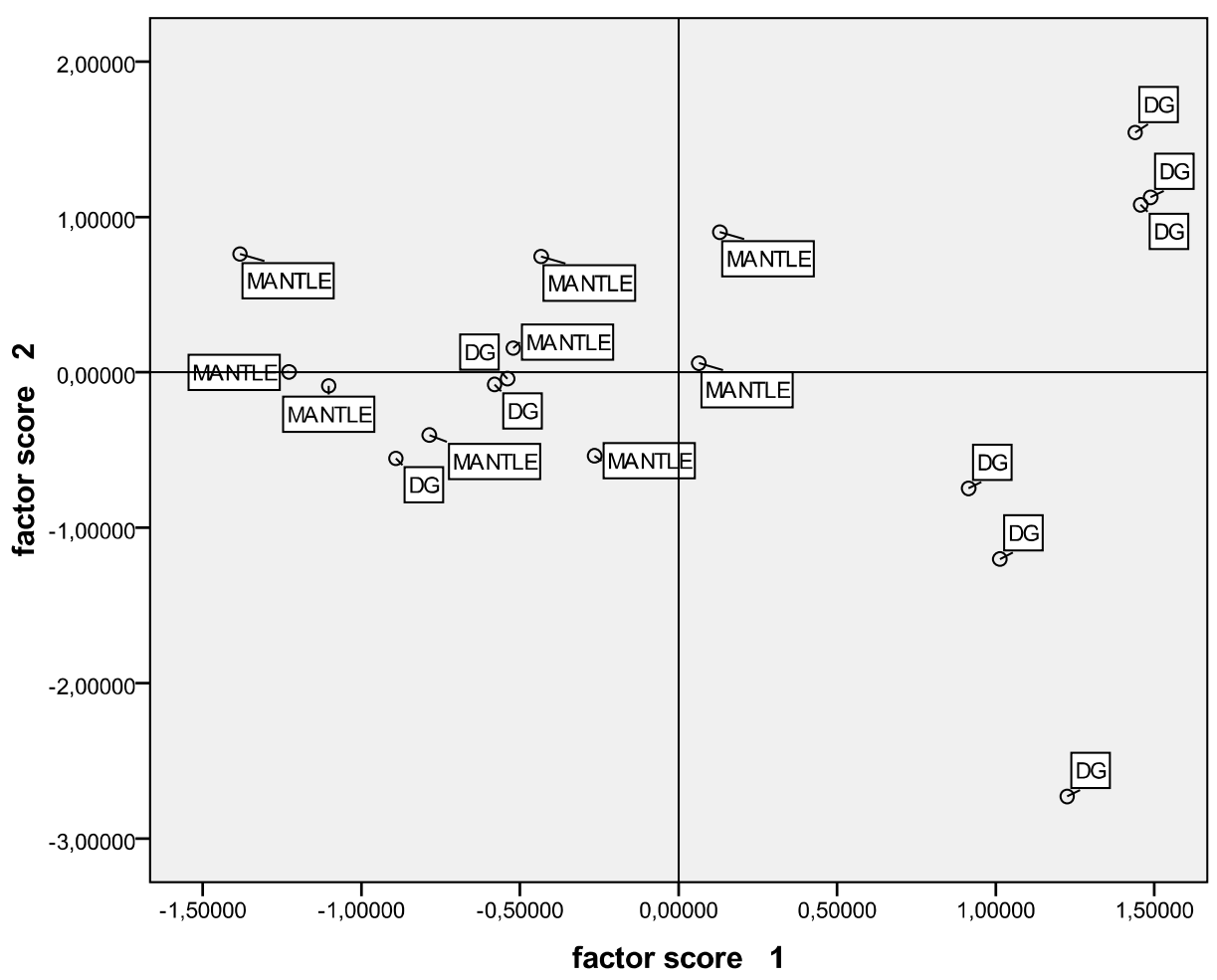




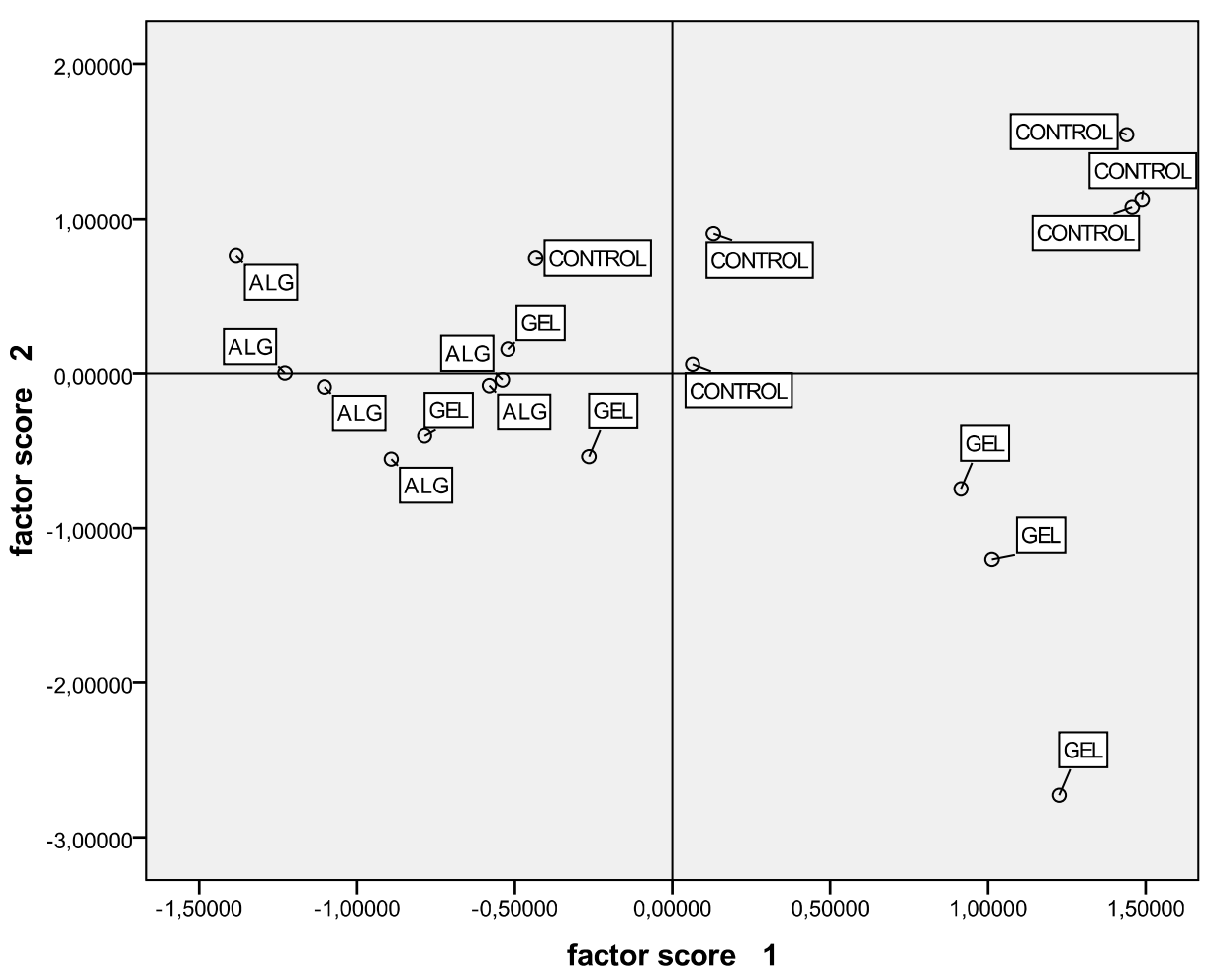

